\title{
How have Economic Evaluations in Relapsing Multiple Sclerosis Evolved Over Time? A Systematic Literature Review
}

\author{
Anggie Wiyani (D) $\cdot$ Lohit Badgujar $\cdot$ Vivek Khurana $\cdot$ Nicholas Adlard
}

Received: June 2, 2021 / Accepted: July 6, 2021 / Published online: July 19, 2021

(C) The Author(s) 2021

\begin{abstract}
Introduction: The introduction of diseasemodifying therapies (DMTs) for relapsing multiple sclerosis (RMS) over the last two decades has prompted the economic assessments of these treatments by reimbursement authorities. The aim of this systematic literature review was to evaluate the modeling approach and data sources used in economic evaluations of DMTs for RMS, identify differences and similarities, and explore how economic evaluation models have evolved over time.

Methods: MEDLINE ${ }, \quad$ Embase ${ }^{\circledR}$, and EBM Reviews databases were searched using Ovid ${ }^{\circledR}$ Platform from database inception on 25 December 2019 and subsequently updated on 17 February 2021. In addition, health technology assessment agency websites, key conference proceedings, and gray literature from relevant
\end{abstract}

Supplementary Information The online version contains supplementary material available at https:// doi.org/10.1007/s40120-021-00264-1.

A. Wiyani $(\bowtie) \cdot$ V. Khurana

Novartis Corporation (Malaysia) Sdn. Bhd., Petaling Jaya, Malaysia

e-mail: anggie.wiyani@novartis.com

L. Badgujar

Novartis Healthcare Pvt. Ltd, Hyderabad, India

N. Adlard

Novartis Pharma AG, Basel, Switzerland websites were screened. The quality of included studies was assessed using the Drummond and Philips checklists.

Results: A total 155 publications and 30 Health Technology Assessment (HTA) reports were included. Most of these were cost-utility analysis (73 studies and 25 HTA reports) and funded by medicines manufacturers $(n=65)$. The top three countries where studies were conducted were the USA $(n=29)$, the UK $(n=16)$, and Spain $(n=10)$. Studies predominantly used Markov cohort models (94 studies; 25 HTAs) structured based on the Expanded Disability Status Scale (EDSS) with 21 health states (20 studies; 12 HTA reports). The London Ontario and British Columbia data sets were commonly used sources for natural history data $(n=33$; $n=13$ ). Twelve studies and ten HTAs from the UK assumed a waning of DMT effect over the long term, while this was uncommon in studies from other countries. Nineteen studies adjusted for multiple sclerosis (MS)-specific mortality estimates, while 18 studies used data from the national life table without adjustment. Studies prominently referred to mortality data that were about two decades old. The data on treatment effect was generally obtained from randomized controlled trials (43 studies; 7 HTAs) or from published evidence synthesis (23 studies; 24 HTAs). Utility estimates were derived from either published studies and/or supplemented with data from RCTs. Most of the models used 
the lifetime horizon $(n=37)$ with a 1-year cycle length $(n=63)$.

Conclusion: As expected, similarities as well as differences were observed across the different economic models. Available evidence suggests models should continue using the Markov cohort model with 21 EDSS-based states, however, allowing the transition to a lower EDSS state and assuming a sustained treatment effect. With reference to the data sources, models should consider using a contemporary MSspecific mortality data, recent natural history data, and country-specific utility data if available. In case of data unavailability, a sensitivity analysis using multiple sources of data should be conducted. In addition, future models should incorporate other clinically relevant outcomes, such as the cognition, vision, and psychological aspects of RMS, to be able to present the comprehensive value of DMTs.

Keywords: Relapsing multiple sclerosis; Disease-modifying therapy; Economic evaluation; Health economics; Systematic review; Multiple sclerosis

\section{Key Summary Points}

This is the first systematic review to comprehensively evaluate existing economic evaluations in relapsing multiple sclerosis (RMS) across the world, and to provide pragmatic recommendations for future economics models.

The cost-utility models in RMS are mostly constructed using a Markov cohort model design, and we recommend to continue using the same structure as it is appropriate and widely accepted by Health Technology Assessment (HTA) bodies across the world.
The existing economic models are completely based on the Expanded Disability Status Scale (EDSS), which is a physical disability scale and hence does not capture other clinically relevant outcomes such as cognition. It is recommended to incorporate such outcomes in the future models to make the models more clinically relevant.

The data sources for the models should be chosen carefully such that they reflect the current disease course and management paradigm for multiple sclerosis.

\section{INTRODUCTION}

Multiple sclerosis (MS) is an inflammatory demyelinating disease of the central nervous system with a variable clinical course. The disease can be broadly classified into relapsing and progressive forms of MS [1]. Relapsing forms of MS (RMS) encompasses all patients with MS who experience relapses, such as clinically isolated syndrome, relapsing-remitting MS (RRMS), and relapsing secondary progressive MS (SPMS), while progressive forms of MS include non-relapsing SPMS and primary progressive MS (PPMS).

Currently, there are 18 disease-modifying therapies (DMTs) approved by the European Medicines Agency or the US Food and Drug Administration (FDA) for the treatment of MS. All DMTs for MS are indicated for the treatment of patients with relapsing forms of MS in the USA, and the labeled indication varies in the European Union according to the disease activity, with the exception of mitoxantrone that is approved for progressive MS [2]. Ocrelizumab is the only DMT approved for PPMS [3], while siponimod and diroximel fumarate are the only DMTs approved for active SPMS as well as RMS $[4,5]$. Considering only a few DMTs are approved for use in progressive forms of MS, this review focuses on RMS for which several different DMTs are available. Furthermore, the 
introduction of new DMTs over the last two decades has prompted economic evaluations to estimate the economic benefits, long-term clinical benefits, and consequently, the value for money of DMTs, with the overall aim to inform healthcare decision-making and funding decisions [6].

Therefore, it is hardly surprising that economic evaluations of DMTs have recently been the topic of systematic reviews, albeit with different areas of focus. One review focused on evaluating the quality of economic evaluations using available instruments while another specifically reviewed cost-effectiveness analyses employing a long-term time horizon $[6,7]$. Other reviews were particularly interested in aspects related to modeling techniques [8-12]. Of particular interest, one review worked on identifying economic modeling methods, data sources, and assumptions of the cost-effectiveness analyses of DMTs; however, this economic modeling-focused review was limited to studies conducted in the UK and the RRMS population [8]. Therefore, it is important to include models developed outside the UK into this systematic review to paint the complete picture of economic evaluation studies of DMTs for RMS that have been undertaken globally. Moreover, as economic evaluations of DMTs play a significant role in informing healthcare decisionmaking and thus impacting patient care in RMS, performing a systematic review in this area will improved understanding of the differences and similarities across models, especially in terms of model structure and assumptions. Subsequently, this will help to identify areas for improvements and developments in future economic models in RMS, such that the evidence informing decision-makers and payers can be presented in a consistent manner and fully represent the value of DMTs in RMS.

The aim of this systematic literature review (SLR) was to evaluate the modeling approach and data sources used in economic evaluation of DMTs for RMS to identify differences and similarities between models, as well as the evolution of models in RMS over time. This SLR builds upon the previous systematic reviews of economic evaluations of DMTs in MS by expanding the review to include studies in the
RMS population regardless of the country of study.

\section{METHODS}

An SLR was performed to identify the evidence pertaining to economic evaluations of DMTs in RMS using a robust methodology as recommended by the National Institute of Health and Care Excellence (NICE) [13]. The search and reporting of the systematic review followed the Preferred Reporting Items for Systematic Reviews and Meta-Analyses (PRISMA) statement [14], and a protocol with predefined inclusion and exclusion criteria was developed. The SLR was subsequently updated in January 2021 to incorporate recent studies. The update follows the inclusion and exclusion criteria of the parent SLR. The protocol summary, search terms, and search dates of both the parent and SLR update are presented in the Electronic Supplementary Material (ESM).

The search for economic evaluation studies of adults with RMS (aged $\geq 18$ years) published in English was conducted in several electronic databases, such as MEDLINE ${ }^{\circledR}$, Embase ${ }^{\circledR}$, and Evidence-Based Medicine (EBM) Reviews through the Ovid ${ }^{\circledR}$ platform. In the parent SLR, these databases were searched from the date of inception up to 20 December 2019 and in the SLR update, the database review was up to 15 February 2021. In addition, the Database of Abstracts of Reviews of Effects (DARE), National Health Service Economic Evaluation Database (NHS EED), and Health Technology Assessment (HTA) database were searched through the Centre for Reviews and Dissemination (CRD) York database from the date of inception up to 5 March 2020. These databases were not searched in the SLR update in 2021 as the DARE and NHS EED databases were not updated after 31 March 2015 and the HTA database was not updated after 31 March 2018. In addition, congress abstracts, HTA agency websites, the Cost-Effectiveness Analysis (CEA) registry, the University of Sheffield Health Utilities Database (HUD), the EQ-5D Publications Database, and bibliography of relevant reviews were hand searched in 


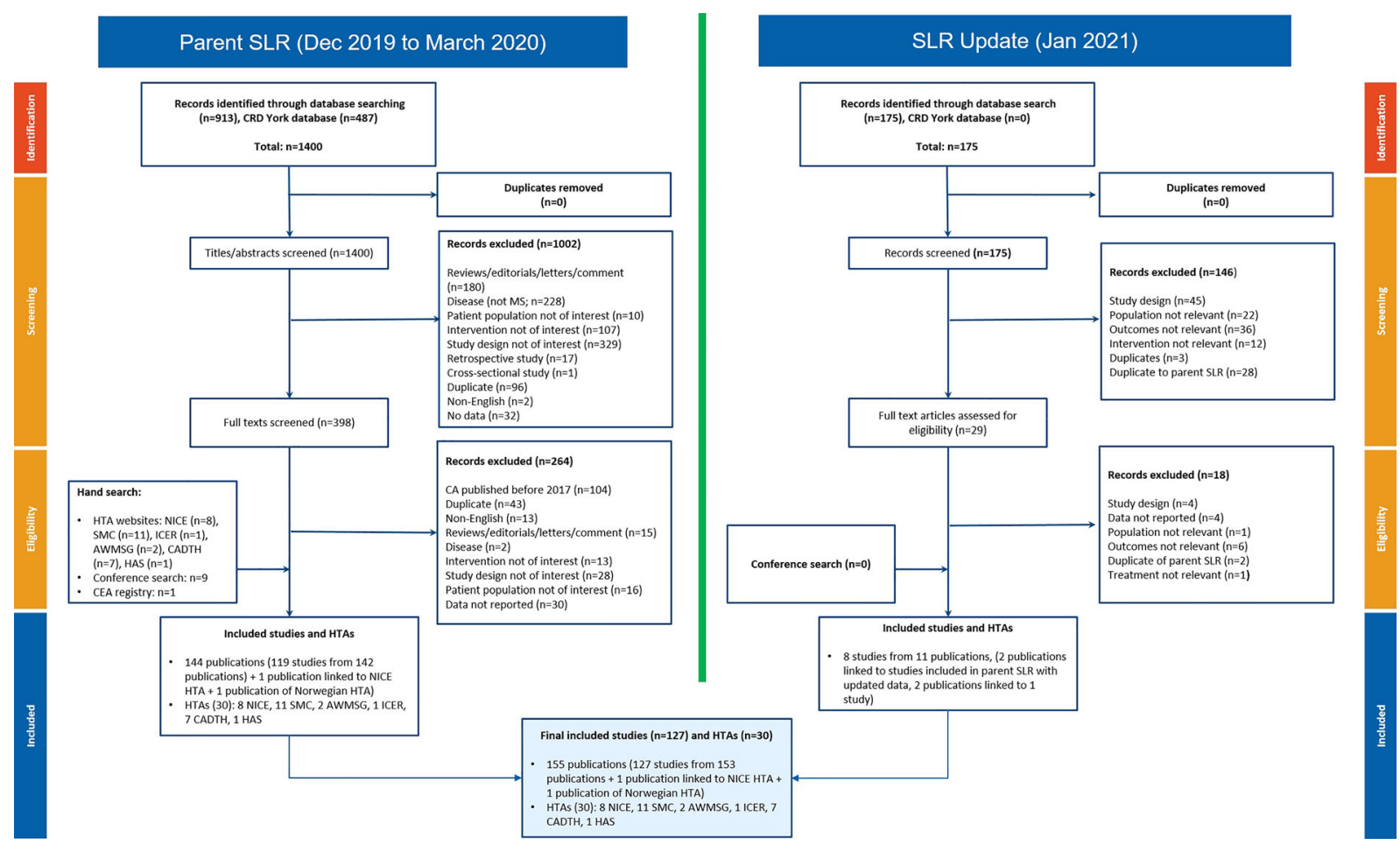

Fig. 1 PRISMA diagram for study identification in the SLR and cumulative number of included studies. $A W M S G$ All Wales Medicines Strategy Group, $C A$ conference abstract, CADTH Canadian Agency for Drugs and Technologies in Health, $C E A$ cost-effectiveness analysis, $C R D$ Centre for Reviews and Dissemination, HAS Haute Autorité de Santé, HTA Health Technology Assessment,

both the parent SLR and SLR update to include relevant studies.

Each citation was screened by one reviewer, and the decisions were validated by a second reviewer. Citations that did not match the eligibility criteria were excluded at "first pass"; where unclear, citations were included. Duplicates of citations were also excluded at the firstpass stage. In the second stage, each full text was screened by one reviewer, and the decisions were validated by a second reviewer. Data from the included studies were extracted into the data extraction sheet by a single reviewer, and the quality and completeness of the data were thoroughly checked by a second reviewer. All the extracted studies were critically appraised using the Drummond [15] and Philips [16] checklists.
ICER Institute for Clinical and Economic Review, $M S$ multiple sclerosis, NICE National Institute of Health and Care Excellence, NIPH The Norwegian Institute of Public Health, PRISMA Preferred Reporting Items for Systematic Reviews and Meta-Analyses, SLR systematic literature review, $S M C$ Scottish Medicines Consortium

The study did not require informed consent or institutional review board approval, as no identifiable patient information was extracted. This article is based on previously conducted studies and does not contain any new studies with human participants or animals performed by any of the authors.

\section{RESULTS}

The database searches in the parent SLR retrieved 1400 citations. After initial screening of titles and abstracts, 398 articles were selected for full-text screening and, finally, 119 studies from 142 publications, one publication linked to a National Institute for Health and Care Excellence (NICE) HTA report, one publication 


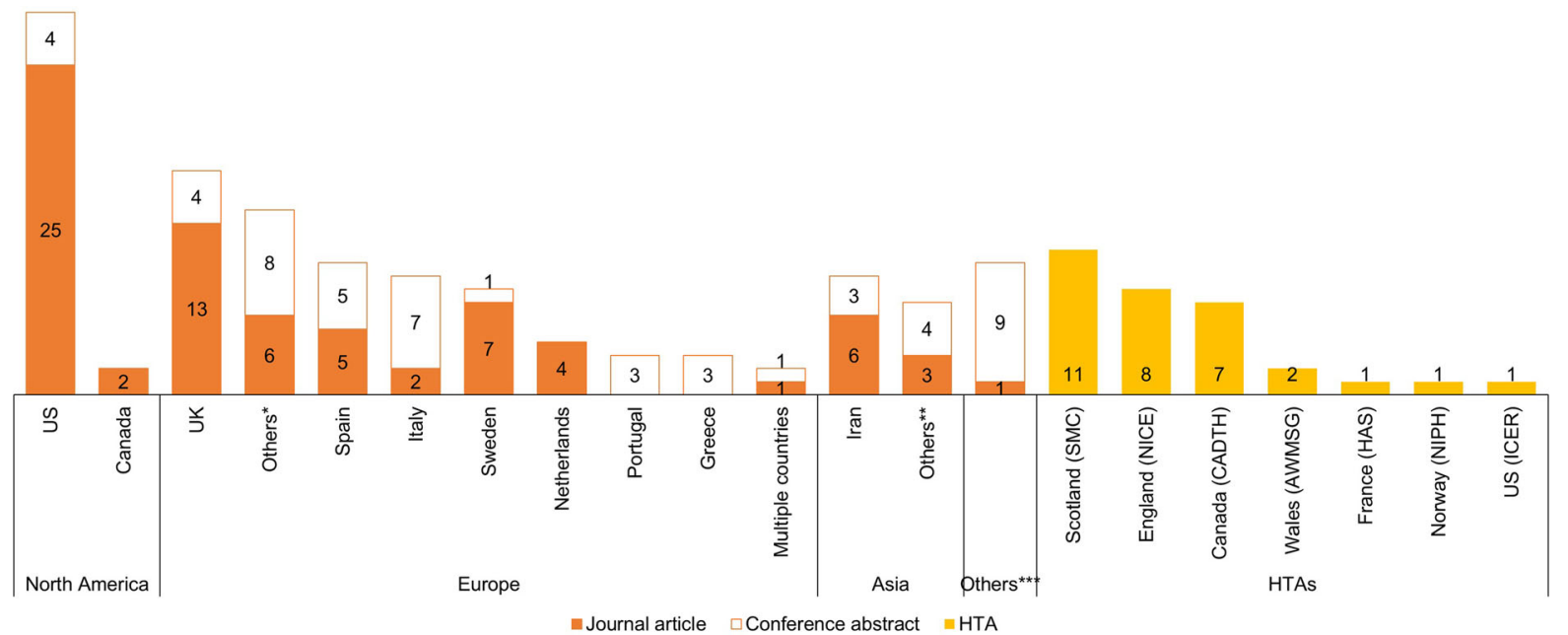

Fig. 2 Geographic region of included studies and HTA reports. Others* refers to the European countries of Austria $(n=1)$, Bulgaria $(n=2)$, Cyprus $(n=1)$, Czech $(n=1)$, Finland $(n=1)$, France $(n=2)$, Germany $(n=2)$, Ireland $(n=1)$, Norway $(n=1)$, Russia $(n=1)$, Serbia $(n=1)$. Others** refers to the Asian

by the Norwegian Institute of Public Health (NIPH) HTA, and 30 HTA reports were included in the parent SLR (Fig. 1). The database searches in the SLR update retrieved 175 citations. After first screening of titles and abstracts, 146 articles were excluded and 29 articles were selected for full-text screening. Subsequently, 11 studies passed the full-text screening, of which two studies $[17,18]$ were linked to two studies included in the parent SLR $[19,20]$, and one conference abstract [21] was linked to a full-text journal article [22]. Finally, eight studies from nine publications were included in the SLR update. Cumulatively, 155 publications and 30 HTAs from the parent SLR and SLR update were included (Fig. 1). When reporting the results, the publication linked to the NIPH HTA is categorized as an HTA, therefore the number of HTAs considered in the Results section is 31 . Critical appraisal of the included studies was conducted using the Drummond [15] and Philips [16] checklists based on the recommendations in the NICE guidelines. countries of China $(n=1)$, Kazakhstan $(n=1)$, Lebanon $(n=1)$, Saudi Arabia $(n=2)$, South Korea $(n=1)$, Thailand $(n=1)$. Others ${ }^{* * *}$ refers to the countries of Argentina $(n=1)$, Brazil $(n=2)$, Chile $(n=1)$, Colombia $(n=4)$, Egypt $(n=1)$, Peru $(n=1)$

\section{Critical Appraisal}

The full results of the critical appraisal of included studies and HTAs using the Drummond and Philips checklist are provided in the ESM.

In summary, the results from the Drummond checklist show that $93 \%$ of studies were able to meet the criteria on study design, and at least $50 \%$ of studies met the criteria on reporting methods of data collection. However, the criteria on reporting the methods of evidence synthesis, the relevance of including productivity changes, and reporting the quantities of resource use separately were not met by $83 \%$ of the studies. Critical appraisal of HTAs using the Drummond checklist show that $83 \%$ of HTAs were able to meet the criteria on study design and that at least $50 \%$ of HTAs met 11 criteria on analysis and interpretation of results. However, several criteria on data collection, criteria on reporting productivity changes separately, reporting resource use quantities separately, addressing generalizability issue, and providing justification on discount rate choice were met by less than $50 \%$ of HTA reports. 
The results from the Philips checklist show that at least eight criteria were met by at least $50 \%$ studies and HTA reports. The criteria on half-cycle correction, assumption on continuation of treatment effect, and model consistency were met by less than $50 \%$ of studies and HTAs.

\section{Study Characteristics}

Overall, 73 studies and 25 HTA reports were cost-utility analyses, 16 studies were cost-effectiveness analyses, five studies and three HTAs were cost-minimization analyses [23-30], and six studies were budget impact analyses [31-36]. Furthermore, 17 studies comprised multiple economic evaluations [18, 22, 37-51], six were cost-consequences analyses [52-57], two were cost-saving analyses [58, 59], one was a cost-benefit analysis [60], and one was a costoffset analysis [61]. A complete list of the type of economic evaluation employed by the studies is available in the ESM

In terms of the funding source, of the 81 studies reporting their funding source, only one study was funded by a university [42]. A majority of studies were funded by pharmaceutical companies ( $n=65$ ), while seven studies were funded by government institutions $(n=7)$ [40, 62-67]; eight studies received no funding $[43,68-74]$.

Geographically, of the 127 included studies, a majority were from the USA $(n=29)$, followed by the UK $(n=17)$ and Spain $(n=10)$ $[24,50,53,59,75-80]$. HTA reports were mostly from Scotland $(n=11)[29,30,81-89]$, followed by England $(n=8)$ [90-97], and Canada $(n=7)$ [28, 98-103] (Fig. 2). Eight HTA reports from Australia (Pharmaceutical Benefits Advisory Committee) were identified; however, they were not included in this review as the information on the reports was redacted. A complete list of the country origin of studies is available in the ESM.

\section{Modeling Approach}

Most studies $(n=94)$ and HTA reports $(n=25)$ constructed Markov cohort models. The remaining studies used spreadsheet-based cohort models $(n=9)$ [38, 39, 69, 104-109], discrete event simulation (DES; $n=4$ ) [110-113], a simulated decision tree $(n=1)$ [114], individual-level simulation models $(n=3)$ [37, 40, 57, 115], and microsimulation $(n=1)$ [116]. A consistent approach was seen in most studies that constructed Markov cohort models, wherein models were structured per the Expanded Disability Status Scale (EDSS), a widely used scale to quantify disability in MS. The complete data table is presented in the ESM. Categories of the model structure discussed in this review were identified by extracting the information explicitly being presented by the author and categorizing it into groups that fit best. The categories referred to in this review were adapted from the previous work by Brennan et al. [117], which separated cohort- and individual-level models, and Salleh et al. [118], which distinguished different simulation modeling techniques, when applicable. The definition of model types considered in this review is presented in the ESM.

\section{Markov Model Health States}

The most common Markov model structure consists of 21 health states: ten EDSS-based states each in RRMS and SPMS and one death state (20 studies, 12 HTA reports). Fourteen studies constructed a seven-state Markov model: four EDSS states in RRMS, two relapse states, and one death state. In the seven-state Markov model, the EDSS state was grouped into few limitations in mobility (EDSS 0.0-2.5), moderate limitations in mobility (EDSS 3.0-5.5), walking aid or wheelchair required (EDSS 6.0-7.5), restricted to bed (EDSS 8.0-9.5), and death (EDSS 10 or natural causes of death). Nine studies [47, 78, 119-125] and three HTA reports $[88,97,103]$ constructed models consisting of 11 health states: ten EDSS states per the EDSS (EDSS 0-9) and one death state. The remaining studies had a Markov model in which the number of states varied between three and 21. A complete list of Markov model health states constructed in the studies is available in the ESM.

A Markov model of 21 health states stems from the model evaluating interferons and glatiramer acetate by the School of Health and 
Related Research of the University of Sheffield (ScHARR) [126] using 0.5-point increments in the EDSS. A submission to NICE for natalizumab [127] and a publication by Gani et al. [128] were the first to illustrate the schematic of this model. This model structure was adapted by subsequent economic evaluation studies, especially in the UK, as well as in HTA submissions to NICE.

Models that included 11 health states did not include SPMS-specific health states on the basis that conversion to SPMS can occur at a range of EDSS scores, patients of both subtypes are reported at many EDSS levels, and mean costs and quality of life are not dependent on MS subtypes [121, 129-132]. These arguments were supported by recent natural history cohort studies, i.e., the Swedish MS cohort and British Columbia MS cohort [130, 133], and by results from observational studies in Sweden, Germany, and UK [129, 131, 134].

The seven-state Markov model originated from a US study by Prosser et al. [135] and consists of four EDSS states, two relapse states, and one death state. The EDSS states pooled the RRMS, SPMS, and RMS populations because the authors considered MS to be a disease with broad activity, of which disability survival curves do not differ by MS type at the time of diagnosis, and health states in terms of costs and quality of life do not differ between MS subtypes $[135,136]$.

\section{Time Horizon and Cycle Length}

The time horizon in the models varied considerably between 1 and 50 years up to the lifetime horizon. Most models used the lifetime horizon $(n=37)$, followed by 50-year $(n=22)$ and 10-year $(n=21)$ time horizons. DES models appear to be consistent, as three of four DES models used the lifetime horizon $[110,112,113]$. The most common cycle length used by the models was 1 year $(n=63)$, followed by 3 months $(n=12)$ and then 1 month $(n=10)[42,43,50,64,68,71,73,76,137,138]$. A data table with data of time horizon and cycle length from all included studies is available in the ESM.

\section{Model Inputs}

\section{Natural History of the Disease}

This review found studies referred to data from clinical trials, MS natural history studies, or both. Overall, across regions, more studies referred to natural history studies than clinical trials, as shown in Fig. 3.

In total, 40 studies sourced data from natural history studies, 11 studies supplemented data from published natural history studies with data from clinical trials [51-53, 107, 139-145], and nine studies referred to clinical trials alone $[67,75,116,130,132,146-149]$. Three studies extracted data from previously published economic evaluations $[22,125,150]$.

Overall, the most common source of the natural history data was the London Ontario data set $(n=33)$. Another source was the British Columbia data set, which was sourced by 13 studies [42, 46, 77, 78, 119-121, 124, 144, 151154]. Among these, four studies $[42,119,144,152]$ coupled the data with the London Ontario data set, seven studies supplemented the London Ontario data set with a Sweden registry data set, three of which were US studies [71, 137, 155], while the remaining were studies from Europe $(n=2)$ [50, 76] and Iran $(n=2)$ [43, 156]. Two studies included data from a country-specific registry data together with the London Ontario data set: one Italian study [157] and one Finnish study [158].

The most common approach in the HTA models was to supplement data with those from clinical trials with published studies $(n=12)$. Of these, nine HTA models used the London Ontario data set $[85,90,92-94,99,100$, $159,160]$ while the remaining used the British Columbia data set $(n=1)$ [101] or both $(n=2)$ $[95,102]$. Other HTAs sourced data from the British Columbia data set alone $(n=6)$ [88, 89, 95-97, 103], the London Ontario data set alone $(n=4)[91,98,161,162]$, or randomized controlled trials (RCTs; $n=3$ ) $[86,91,110]$.

\section{Treatment Effect}

Most studies sourced treatment-effect data directly from RCTs $(n=43)$. Fewer studies sourced data from published evidence synthesis 


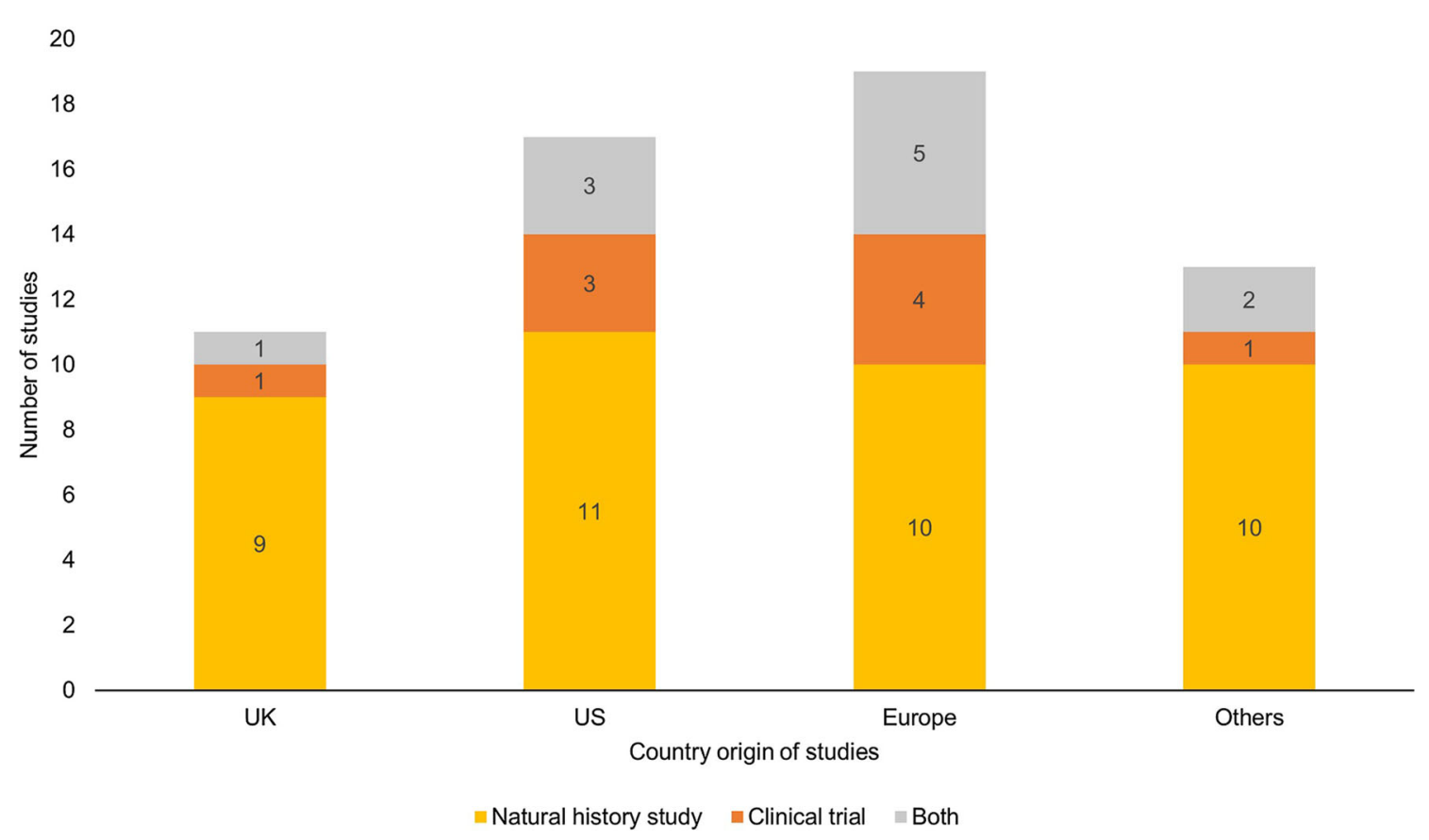

Fig. 3 Sources of the natural history of multiple sclerosis data in economic evaluations included in this review. "Others" refers to Asia (China, Iran, Saudi Arabia, Thailand), Brazil, Canada. DMT Disease-modifying therapy, RMS relapsing MS

[network meta-analysis (NMA)/mixed treatment comparison (MTC)/indirect treatment comparison (ITC)/SLR] $(n=23)$ and previously published economic evaluations $(n=8)$ [21, 27, 64, 153, 156, 163-165]. Meanwhile, most HTA reports derived estimates by synthesizing evidence (NMA/MTC/ITC/SLR; $n=24$ ). Only seven HTAs sourced treatment-effect data directly from RCTs [28, 30, 81, 84, 95, 100, 110].

\section{Efficacy Waning}

Overall, 12 studies assumed a treatment-waning effect, following the approach advocated by NICE in some of their previous appraisals. These studies assumed a treatment-waning effect of $25 \%$ after 2 years and $50 \%$ after 5 years of treatment. These studies originated from the UK $(n=4)[113,121,151,166]$, Europe $(n=3)$ [31, 154, 167], Iran $(n=2)[144,168]$, Canada $(n=1) \quad$ [124], USA $(n=1)$ [119], and Chile $(n=1)$ [48]. Similarly, the base-case analysis of ten HTAs in the UK $[83,87,88$, $91,92,94-97,110]$ assumed that the treatment effect would fall to $75 \%$ after 2 years of treatment and to $50 \%$ after 5 years of treatment. Meanwhile, six HTAs did not assume an efficacy waning in their base-case analysis yet included it in the sensitivity analysis [81, 86, 89, 93, 96, 159]. Moreover, 14 studies assumed a sustained treatment effect over time.

\section{Utility Values}

Studies tended to use utility data available in the literature, while some HTAs coupled the literature data with data from clinical trials. Thirteen studies in the UK $[37,46,49,63$, 70, 112, 113, 128, 144, 146, 151, 166, 169], seven studies in the USA $[40,41,71-73$, $114,137]$, and 11 studies in Europe [50, $76,130,132,140,142,145,147,158,170,171]$ referred to published country-specific studies to derive utility inputs. Country-specific studies were used whenever available, while data from published studies from other countries were used in 12 studies $[40,64,66,74,114$, $119,124,149,150,154,156,163]$ and five HTAs [98-100, 102, 161]. The most common publication referred to by the UK studies was that of Orme et al. [172] $(n=8)[46,49,70,112,113$, $128,144,166]$, while in the USA, the most common publication referred to was that of Prosser et al. [173] $(n=4)[71-73,137]$. Another 
approach was to use data from clinical trials to supplement data from utility studies $(n=9)$ $[67,78,121,125,141,143,157,167,174]$.

Models in HTAs in the UK sourced utility data from either published studies supplemented with RCT data $(n=12)$ $[83,85,86,88,89,91,92,94-97,159]$ or published studies alone $(n=10)$ [81, 87, 90-93, $95,110,160,161]$. NICE HTA reports consist of the submitted model by the manufacturer and the model developed by the NICE Evidence Review Group; therefore, the same citation can be reported multiple times. One UK study in particular became the main reference for UK HTAs [172], as this study estimated utility values from the UK MS Trust Database. Most HTAs outside of the UK sourced utility value data directly from published studies $(\mathrm{n}=7)$. Among these seven HTAs, four [98, 100, 102, 161] referred to studies conducted in other countries, particularly a UK study [172]. In addition, one HTA from Canada [101] and one from the USA [162] combined data from studies with those of clinical trials.

\section{Mortality}

Overall, 38 studies reported the source of mortality data inputs. While 19 used adjusted data from the national life table for MS-specific mortality risk using mortality multipliers from published studies, 18 studies used data from the national life table of the general population (age- and gender-adjusted) without adjusting for MS. The published study most commonly referred to was that of Pokorski [175] $(n=14)$ $[67,74,119,128,138,139,141,143$, $145,150,157,165,166,174]$. Other published mortality studies referred to were those of Hirst et al. [176], which was referred to by one study [152], Cutter et al. [177], which was referred to by one study [120], and Sadovnick et al. [178], which was referred by two studies $[154,166]$. Three studies used specific mortality data of a MS population: one study [41] sourced mortality data from pivotal clinical trials of interferon beta-1b $[179,180]$, one [158] from the Finland MS registry [181], and one [130] from the Danish MS registry [182].

Most HTA models adjusted data from the respective national life table using the MS mortality multiplier from the Pokorski study [175] $(n=11)$ [90-96, 100-102, 162]. Three HTAs used the MS mortality multiplier from other published studies, with one HTA [160] using the mortality multiplier from the study by Leray et al. [183], one HTA [99] using the MS mortality multiplier from the study by Sadovnick et al. [178], and the last [103] using the mortality multiplier from the study of Kingwell et al. [184]. Two HTAs [98, 161] reported no adjustment to the mortality rate of the general population.

\section{Summary}

A summary of the recommendations for model characteristics are given in Table 1.

\section{DISCUSSION}

Economic evaluations of DMTs for RMS and the modeling aspects involved play a significant role in informing healthcare decision-making, which will, in turn, impact patient care in MS and eventually patients' outcomes. Moreover, evidence informing decision-makers and payers need to be presented in a consistent manner and fully represent the value of DMTs in RMS. Therefore, it is important to understand the differences and similarities across models, especially in model structure and assumptions, to be able to identify areas for improvements and developments in future economic models in RMS. This study reviewed all published economic evaluation studies and HTAs of DMTs in RMS available to date. While previous reviews have focused on a particular geographic region, i.e., the UK [8], a short time period [190], or the reporting quality of studies [6], to the best of our knowledge, this is the first comprehensive review to examine the trend of model characteristics over the years (Fig. 4) and provide recommendations for future models (Table 1).

Our review suggests that models differ in several assumptions (e.g., long-term treatment effect and EDSS improvement over time) and in the approach in estimating mortality rates. At the same time, there are similarities in modeling aspects, such as the type of model, model 
Table 1 Summary of recommendations for model characteristics

\begin{tabular}{lll}
\hline $\begin{array}{l}\text { Model characteristics } \\
\text { and source }\end{array}$ & Strengths and limitations & Recommendations
\end{tabular}

Modeling approach

1. Markov model

2. Discrete event simulation

2. Non-EDSS-based

health states, e.g., [75]

Model health states

1. EDSS-based health states
The limitation of the Markovian assumption is that the probability of transitioning between states is contingent only on the current EDSS state, regardless of transitions, disease history, or length of time in the current state

The discrete event simulation model can better capture the individual disease journey of MS patients, such as switching between DMTs, long-term AEs, and outcomes as well as individual patient's attributes or comorbidities [112,113]
Disease progression in MS is routinely measured using the EDSS in clinical trials as well as clinical practice [185]

The EDSS has been criticized for lacking measures of cognitive function, an important dimension of MS [186-188]

The Markov model is structured upon the occurrence of exacerbation throughout the patient's disease journey. The strength of this model is its ability to resemble clinical practice in which clinicians tend to record exacerbations. However, this model cannot estimate the magnitude of benefit in terms of delayed progression in disability
Future models are recommended to continue using the Markov cohort model, and if data available to include the outcome of individual patients, which may preclude patients to continue their treatment, incorporate the effect of long-term AEs, and take into account individual patient attributes that may affect the rate of disease progression for which an individual-based simulation such as a discrete event simulation might be more appropriate

Currently, models are focused on capturing the benefit of DMTs in terms of delaying progression in physical disability or avoiding relapse, while ignoring the impact on cognitive ability and other clinically relevant outcomes. Future models are recommended to explore how the cognition, vision, and psychological components of RMS can be captured. A cognitive performance outcome measure, such as the Symbol Digit Modalities Test, is available to measure information processing speed ability [188, 189] 
Table 1 continued

\begin{tabular}{lll}
\hline $\begin{array}{l}\text { Model characteristics } \\
\text { and source }\end{array}$ & Strengths and limitations & Recommendations \\
\hline
\end{tabular}

Model inputs

1. Natural history of disease

\section{a. London Ontario \\ data set, e.g.,}

$[127,135,137]$

data set, e.g.,

$[46,119,121]$

2. Treatment effect

a. RCT
The London Ontario data set consisted of relatively old data from the 1980 s, censored improvement in the EDSS, and had a smaller cohort size compared with the British Columbia data set. However, many studies used this data set, as it has separate transition probabilities for RRMS and SPMS patients as well as a probability of transition from RRMS to SPMS

The British Columbia data set is a more recent data set that allows for EDSS score improvement and has a larger cohort size

RCTs demonstrate the efficacy and safety of DMTs, which also become the basis of drug marketing authorization. However, where multiple DMTs are available, data from RCTs may not include all appropriate comparators available in clinical practice

b. Evidence synthesis (NMA/MTC/ITC/ SLR)
A previous SLR showed that one of the sources of uncertainty in the economic evaluation in RMS is the absence of head-to-head RCTs between the intervention and comparator of interest $[6,12]$. Using techniques such as NMA or ITC is useful when data from RCTs are not available, as they are quite flexible to include various DMTs of interest
Clinical practice of MS management has vastly changed over the years, which may challenge the assumption by the London Ontario data set that improvement in the EDSS is not possible. There is a need for a new natural history data that reflects current clinical practice. Future models may consider using recent data set and assessing the effect of using both data sources by performing a sensitivity analysis

It is recommended to use head-to-head RCTs between DMTs or published NMAs or ITCs if RCTs are not available $[9,12,190]$ 
Table 1 continued

\begin{tabular}{lll}
\hline $\begin{array}{l}\text { Model characteristics } \\
\text { and source }\end{array}$ & Strengths and limitations & Recommendations
\end{tabular}

\section{and source}

3. Efficacy waning

a. Sustained efficacy

Owing to data limitations, previous models have made assumptions that treatment effect is constant over the time horizon. This assumption may hold true if there is no evidence to prove otherwise. Evidence from long-term studies of fingolimod, ocrelizumab and other DMTs show sustained benefit in clinical and magnetic resonance imaging outcomes

b. Waning of efficacy

\section{A recent meta-analysis and long-term} effectiveness study showed an inverse agedependent association with efficacy, which may support the view that treatment effect decreases over time [191, 192]. Furthermore, some argue that neutralizing antibodies is affecting DMTs and RCTs do not provide data for a sufficient time period relative to the chronic nature of RMS [92]. However, uncertainty remains on the magnitude of the treatment waning. Most models assumed a decrease of $25 \%$ after 2 years and later $50 \%$ after 5 years, which has been set arbitrarily and has not been supported by long-term studies [193-195]

4. Utility values

a. Published countryspecific studies and/or RCTs

b. Published studies from other countries
This approach follows the recommendation where utility data are obtained from the target population of the intervention (in the same jurisdiction/country) $[196,197]$

Using utility data from other countries poses an uncertainty regarding the transferability of these utilities, as different populations have different value judgments
Address the uncertainty of treatment effect after the time period of RCTs by performing a sensitivity analysis on the magnitude of waning in the long-term or provide treatment-effect estimates based on longterm data if available $[8,12,190]$

It is considered best practice to use utility values from the target population of the intervention [13, 196, 197]. Considering the scarcity of data, it is recommended to conduct a sensitivity analysis with various sources of data inputs [190] 
Table 1 continued

\begin{tabular}{|c|c|c|}
\hline $\begin{array}{l}\text { Model characteristics } \\
\text { and source }\end{array}$ & Strengths and limitations & Recommendations \\
\hline \multicolumn{3}{|l|}{ 5. Mortality } \\
\hline $\begin{array}{l}\text { a. National life } \\
\text { table of the general } \\
\text { population }\end{array}$ & $\begin{array}{l}\text { Studies taking this approach assumed that the } \\
\text { all-cause mortality risk for the MS cohort } \\
\text { was the same as that for the general } \\
\text { population and applied probability of death } \\
\text { due to MS only to patients in severe EDSS } \\
\text { states. MS is a chronic disease and affects } \\
\text { patients throughout their life; not adjusting } \\
\text { the mortality risk of the general population } \\
\text { would underestimate the impact of living } \\
\text { with the disease }\end{array}$ & $\begin{array}{l}\text { Since several mortality studies based on } \\
\text { observational data have shown that MS } \\
\text { patients pose higher mortality risk, it is } \\
\text { recommended that future models follow this } \\
\text { approach and refer to recent evidence }\end{array}$ \\
\hline $\begin{array}{l}\text { b. Adjusted national } \\
\text { life table for MS- } \\
\text { specific mortality risk }\end{array}$ & $\begin{array}{l}\text { Studies taking this approach refer to published } \\
\text { evidence on mortality risk of MS patients } \\
\text { [175-178], which demonstrated the higher } \\
\text { mortality rates of MS patients compared } \\
\text { with general population and that mortality } \\
\text { rates increase with higher EDSS scores }\end{array}$ & \\
\hline
\end{tabular}

$A E$ Adverse event, DMT disease-modifying therapy, EDSS Expanded Disability Status Scale, ITC indirect treatment comparison, $M S$ multiple sclerosis, $M T C$ multiple treatment comparison, $N M A$ network meta-analysis, $R C T$ randomized controlled trial, $R M S$ relapsing MS, RRMS relapsing-remitting MS, SLR systematic literature review, SPMS secondary progressive MS

structure, time horizon, and the source of natural history data. Additionally, it is apparent from this review that medicines manufacturers have taken a leadership in economic modeling to generate economic evidence of DMTs in RMS due to the requirement by HTA agencies for funding or reimbursement decisions. It is fair to conclude the evolution of economic modeling methods in this area occurred in conjunction with the development of new DMTs by medicines manufacturers.

First, evidence from this review suggests that the majority of studies consistently used a Markov cohort model. Previous studies have pointed out the limitations of both Markov cohort models in modeling RMS disease and of EDSS in representing cognitive impairment related to MS [46, 119, 187]. However, only three studies used the DES model to overcome this limitation and to capture the heterogeneity and complexity of MS and its treatments [111-113]. Furthermore, it is important to highlight that only one model used in the HTA reports was a DES model and the rest were Markov cohort models, explaining the prominent use of Markov cohort model in economic evaluation studies in RMS. Evidence suggests that economic models continue constructing a Markov cohort model to align with HTA agencies' guidance. A DES model should be considered when individual patient-level data are available and when there is a need to incorporate specific events such as treatment switching to evaluate long-term outcomes [113].

Secondly, we found that most models were structured based on the EDSS scores, mainly as 21 EDSS-based health states covering ten states in RRMS, ten states in SPMS, and one death state. This structure can characterize the relapsing forms of MS, including the transition 


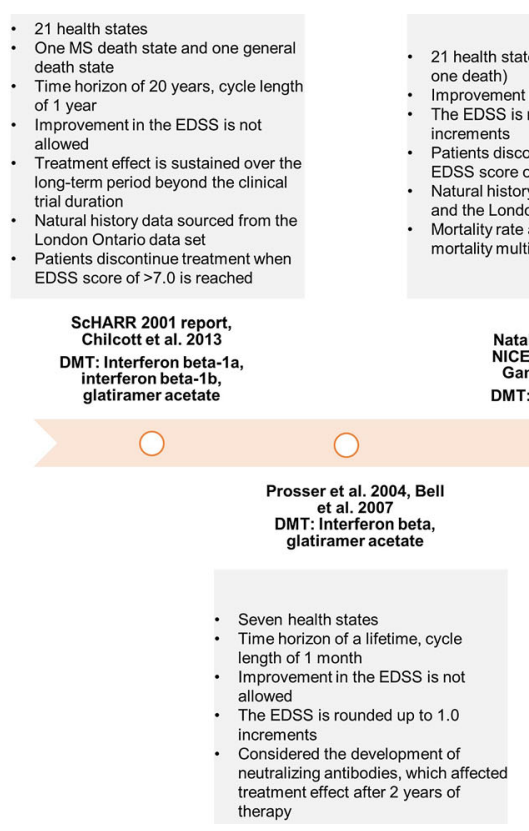

Fig. 4 Timeline diagram of evolution of Markov models of RMS over time. EDSS Expanded Disability Status Scale, $G A$ glatiramer acetate, $R C T$ randomized controlled

to SPMS. However, as this structure is solely based on a physical disability scale, this would mean current models do not capture other clinically relevant outcomes of RMS, such as cognition, despite cognitive dysfunction affecting up to $70 \%$ of patients [198]. This may therefore imply that current models undervalue the benefits of new therapy where there is a proven effect on elements of cognition. Our recommendations are twofold; first, that the Markov model use the 21 health states when it is structured based on EDSS and, second, that the model structure incorporate other clinically relevant outcomes of MS, such as the cognition.

Though models are consistently structured as a Markov cohort with EDSS-based states, models differ in terms of assumptions. First, regarding the transition to a lower EDSS state wherein prior to 2017 models assumed the effectiveness of DMTs could not alter patients' disability such that a transition to a lower EDSS state was possible. This assumption was in line with the London Ontario data set. Recently, several models assumed that patients could transition to a lower EDSS state (Fig. 4) trial, $R M S$ relapsing MS, $R R M S$ relapsing-remitting MS, ScHARR School of Health and Related Research, SPMS secondary progressive MS

$[46,119,121]$. Indeed, the emergence of this assumption concurred with the new evidence surrounding the natural history of MS by Palace et al. [133] using the British Columbia data set. Indeed, the London Ontario and British Columbia data sets were the prominent sources for the natural history of MS data among the economic models. However, both data sets were obtained from cohorts in the 1970s and 1980s. Therefore, there is a need for a new natural history data set of MS to derive transition probabilities that reflect the current MS disease course in order to better involve decision-making based on the current management paradigm for MS. We recommend incorporating the more recent evidence in the future economic models and assume patients can transition to a lower EDSS state. Additionally, a sensitivity analysis using the London Ontario data set should be performed to understand the impact of the alternative.

Furthermore, differences were observed in the assumption on how the long-term treatment effect is applied in the model, and it varied with the country of study. Most of the 
studies from the UK assumed that treatment efficacy would wane after a certain period of time as a result of NICE imposing this assumption to address the concern over the short clinical trial duration and the formation of neutralizing antibodies that might hamper long-term effectiveness of DMTs [92]. However, studies and HTAs outside the UK, especially those that were recently published, generally did not apply this assumption. In particular, the CADTH Pharmacoeconomic Review Report of Ocrelizumab and NICE Technology Appraisal Guidance of Ocrelizumab (TA533) [96, 101] mentioned that applying such an assumption would double count discontinuations due to efficacy failure, which is likely due to the current practice where patients switch to another therapy when experiencing a lack of treatment response, and that ocrelizumab generates negligible neutralizing antibodies. Indeed, evidence from long-term studies of fingolimod, ocrelizumab, and other DMTs show sustained benefit in clinical and magnetic resonance imaging outcomes [193-195], supporting the no-waning-effect assumption. Acceptance of the nowaning-effect assumption by the Canadian Agency for Drugs and Technologies in Health [101] marked an important milestone. This decision corresponds with our recommendation for future models not to apply the efficacywaning assumption. A sensitivity analysis of an alternative assumption can be performed to evaluate the impact.

Another apparent heterogeneity across models was model inputs, such as mortality and utility data sources. Our review found that despite the availability of a recent evidence by Harding and colleagues [199], the most common source cited for mortality data was the Pokorski et al. study [175]. There are a number of caveats that concern the applicability of data from the Pokorski et al. [175] study as well as data from the Harding et al. [199] study to the current therapeutic environment. First, the number of DMTs currently available compared with the Pokorski et al. [175] era may have an impact on the mortality rates. Second, Harding et al. [199] demonstrated that the mortality rate increases with higher EDSS scores but more substantially at EDSS $\geq 8.0$, contrary to the evidence suggested by the Pokorski et al. [175] study where the mortality rate increases even with a mild disease form. Finally, the finding from the Harding et al. study [199] suggests that the life expectancy for MS patients has improved more than that of the general population. As mentioned above, there are limitations associated with both studies, and we recommend that future models consider using contemporary mortality data for RMS patients. There is a need for further mortality studies to resolve the questions raised.

On similar lines, this review highlights the different approaches taken by studies and HTAs in their utility inputs. Generally, HTAs used data from individual patient-level data from RCTs of the DMTs of interest coupled with data from published utility studies, while economic evaluation studies relied on published utility estimates from the literature. Accordingly, this review also found several studies referring to utility data from other countries $(n=7)$, which could indicate the lack of utility studies in various countries. This might be a concern as several national guidelines recommend the use of utility values from the countries of interest and transferring utility scores across countries might be questionable [197]. Therefore, future models should select their utility source from their respective country whenever available. When local data are unavailable, we suggest conducting a sensitivity analysis with various sources of utility data inputs to assess the magnitude of impact to the cost-effectiveness estimate [190]

To conclude, existing economic models of DMTs in RMS are mostly constructed as Markov cohort models as per the EDSS, which should continue. Furthermore, in light of the availability of many new multiple DMTs in current clinical practice, future models should consider taking the following approach: to allow for the transition to a lower EDSS state; to assume a sustained treatment effect over the long term; to use a contemporary MS-specific mortality data; and to consider the most recent natural history and country-specific utility data. In addition, future models should incorporate other clinically relevant outcomes, such as the cognition, vision, and psychological aspects of 
RMS, to be able to present the comprehensive value of DMTs.

\section{ACKNOWLEDGEMENTS}

Funding. This study was funded by Novartis Pharma AG, Basel, Switzerland. The journal's Rapid Service Fee was funded by Novartis Pharma AG, Basel, Switzerland.

Authorship. All named authors meet the International Committee of Medical Journal Editors (ICMJE) criteria for authorship for this article, take responsibility for the integrity of the work as a whole, and have given their approval for this version to be published.

Authorship Contributions. Anggie Wiyani, Lohit Badgujar, Vivek Khurana, and Nicholas Adlard conceived the study design. Anggie Wiyani, Lohit Badgujar, and Vivek Khurana conducted the review. Anggie Wiyani drafted the initial manuscript. All authors commented on draft versions of the manuscript and approved the final manuscript.

Disclosures. Anggie Wiyani is an employee of Novartis Corporation (Malaysia) Sdn. Bhd., Malaysia. Vivek Khurana is an employee of Novartis Corporation (Malaysia) Sdn. Bhd., Malaysia. Lohit Badgujar was an employee at Novartis Healthcare Pvt. Ltd., India at the time the study was conducted. Lohit Badgujar is currently affiliated with OPEN HEALTH Evidence and Access, India. Nicholas Adlard is an employee of Novartis Pharma AG, Switzerland.

Compliance with Ethics Guidelines. This article is based on previously conducted studies and does not contain any new studies with human participants or animals performed by any of the authors.

Data Availability. All data generated or analyzed during this study are included in this published article/as supplementary information files.
Open Access. This article is licensed under a Creative Commons Attribution-NonCommercial 4.0 International License, which permits any non-commercial use, sharing, adaptation, distribution and reproduction in any medium or format, as long as you give appropriate credit to the original author(s) and the source, provide a link to the Creative Commons licence, and indicate if changes were made. The images or other third party material in this article are included in the article's Creative Commons licence, unless indicated otherwise in a credit line to the material. If material is not included in the article's Creative Commons licence and your intended use is not permitted by statutory regulation or exceeds the permitted use, you will need to obtain permission directly from the copyright holder. To view a copy of this licence, visit http://creativecommons.org/ licenses/by-nc/4.0/.

\section{REFERENCES}

1. Lublin FD, Reingold SC, Cohen JA, et al. Defining the clinical course of multiple sclerosis. Neurology. 2014;83(3):278. https://doi.org/10.1212/WNL. 0000000000000560 .

2. U.S. Food and Drug Administration. Mitoxantrone (novantrone) prescribing information. 2012. https://www.accessdata.fda.gov/drugsatfda_docs/ label/2012/019297s035lbl.pdf. Accessed 24 June 2021.

3. U.S. Food and Drug Administration. OCREVUS (ocrelizumab) prescribing information. 2017. https://www.accessdata.fda.gov/drugsatfda_docs/ label/2017/761053lbl.pdf. Accessed 24 June 2021.

4. U.S. Food and Drug Administration. MAYZENT® (siponimod) Prescribing Information. 2019. https:// www.accessdata.fda.gov/drugsatfda_docs/label/ 2019/209884s000lbl.pdf. Accessed 24 June 2021.

5. U.S. Food and Drug Administration. Vumerity (diroximel fumarate) prescribing information. 2019. https://www.accessdata.fda.gov/drugsatfda docs/label/2019/211855s000lbl.pdf. Accessed $2 \overline{4}$ June 2021.

6. Iannazzo SA-O, Iliza AC, Perrault L. Disease-modifying therapies for multiple sclerosis: a systematic literature review of cost-effectiveness studies. 
Pharmacoeconomics. 2018;36(1179-2027): 189-204. https://doi.org/10.1007/s40273-017-05772.

7. Yamamoto D, Campbell JD. Cost-effectiveness of multiple sclerosis disease-modifying therapies: a systematic review of the literature. Autoimmune Dis. 2012;2012:784364. https://doi.org/10.1155/ 2012/784364.

8. Allen F, Montgomery S, Maruszczak M, Kusel J, Adlard N. Convergence yet continued complexity: a systematic review and critique of health economic models of relapsing-remitting multiple sclerosis in the United Kingdom. Value Health. 2015;18(6): 925-38. https://doi.org/10.1016/j.jval.2015.05.006.

9. Guo S, Pelligra C, Saint-Laurent Thibault C, Hernandez L, Kansal A. Cost-effectiveness analyses in multiple sclerosis: a review of modelling approaches. Pharmacoeconomics. 2014;32(6):559-72. https://doi.org/10.1007/s40273-014-0150-1.

10. Hawton A, Shearer J, Goodwin E, Green C. Squinting through layers of fog: assessing the cost effectiveness of treatments for multiple sclerosis. Appl Health Econ Health Policy. 2013;11(4):331-41. https://doi.org/10.1007/s40258-013-0034-0.

11. Koeser L, McCrone P. Cost-effectiveness of natalizumab in multiple sclerosis: an updated systematic review. Expert Rev Pharmacoecon Outcomes Res. 2013;13(2):171-82. https://doi.org/10.1586/erp.13. 14.

12. Thompson JP, Abdolahi A, Noyes K. Modelling the cost effectiveness of disease-modifying treatments for multiple sclerosis. Pharmacoeconomics. 2013;31(6):455-69. https://doi.org/10.1007/ s40273-013-0063-4.

13. National Institute for Health and Care Excellence (NICE). Single technology appraisal: user guide for company evidence submission template. 2017. https://www.nice.org.uk/process/pmg24/chapter/ instructions-for-companies. Accessed 16 Nov 2020.

14. Moher D, Liberati A, Tetzlaff J, Altman DG. Preferred reporting items for systematic reviews and meta-analyses: the PRISMA statement. Ann Intern Med. 2009;151(4):264-9. https://doi.org/10.7326/ 0003-4819-151-4-200908180-00135.

15. Drummond M, Jefferson TO. Guidelines for authors and peer reviewers of economic submissions to the BMJ. The BMJ Economic Evaluation Working Party. Br Med J. 1996;313(7052):275-83. https://doi.org/ 10.1136/bmj.313.7052.275.

16. Philips Z, Ginnelly L, Sculpher M, et al. Review of guidelines for good practice in decision-analytic modelling in health technology assessment. Health
Technol Assess. 2004;8(36):1-158. https://doi.org/ 10.3310/hta8360.

17. Mantovani LG, Furneri G, Cortesi PA, Santoni L, Prosperini L, Cardillo A. PND42-Cost-effectiveness of dimethyl-fumarate compared to teriflunomide for relapsing remitting multiple sclerosis patients in Italy. Value Health. 2020;23:S630. https://doi.org/ 10.1016/j.jval.2020.08.1367.

18. Ayati N, Fleifel L, Sharifi S, Sahraian MA, Nikfar S. Cladribine tablets are a cost-effective and cost-saving treatment strategy for high disease activity relapsing multiple sclerosis patients in Iran. Mult Scler Relat Disord. 2020;37: 101577. https://doi.org/ 10.1016/j.msard.2019.11.052.

19. Mantovani LG, Furneri G, Cortesi PA, Puma E, Santoni L, Prosperini L. Cost-effectiveness analysis of dimethyl fumarate in the treatment of relapsing remitting multiple sclerosis in Italy. Value Health. 2019;22:S740.

20. Ayati N, Fleifel L, Sharifi S, Sahraian MA, Nikfar S. PND47-Cladribine tablet, as a dominant comparator to natalizumab in high-disease activity relapsing multiple sclerosis patients, in the context of a developing country. Value Health. 2019;22: S745. https://doi.org/10.1016/j.jval.2019.09.1817.

21. Dort T, Kotsopoulos N, Connolly MP, Lundqvist T, Kavaliunas A. The fiscal consequences of public health investments in disease-modifying therapies for the treatment of relapsing-remitting multiple sclerosis in Sweden. Stockholm: ECTRIMS 2019; 2019. Abstract P454. https://onlinelibrary.ectrimscongress.eu/ectrims/2019/stockholm/278814/ thomas.lundqvist.the.fiscal.consequences.of. public.health.investments.in.html?f=menu $\% 3 \mathrm{D} 6 \%$ 2Abrowseby\%3D8\%2Asortby\%3D2\%2Amedia\% 3D3\%2Ace_id\%3D1603\%2Aot_id\%3D21663. Accessed 10 Mar 2021.

22. Kotsopoulos N, Connolly MP, Dort T, Kavaliunas A. The fiscal consequences of public health investments in disease-modifying therapies for the treatment of multiple sclerosis in Sweden. J Med Econ. 2020;23(8):831-7. https://doi.org/10.1080/ 13696998.2020.1757457.

23. Bergvall N, Tambour M, Henriksson F, Fredrikson S. Cost-minimization analysis of fingolimod compared with natalizumab for the treatment of relapsing-remitting multiple sclerosis in Sweden. J Med Econ. 2013;16(3):349-57. https://doi.org/10. 3111/13696998.2012.755537.

24. Crespo C, Izquierdo G, García-Ruiz A, Granell M, Brosa M. Cost minimisation analysis of fingolimod vs natalizumab as a second line of treatment for relapsing-remitting multiple sclerosis. Neurologia. 
2014;29(4):210-7. https://doi.org/10.1016/j.nrl. 2013.04.003.

25. Heisen M, Treur MJ, van der Hel WS, Frequin STFM, Groot MT, Verheggen BG. Fingolimod reduces direct medical costs compared to natalizumab in patients with relapsing-remitting multiple sclerosis in The Netherlands. J Med Econ. 2012;15(6): 1149-58. https://doi.org/10.3111/13696998.2012. 707631.

26. Piena MA, Heisen M, Wormhoudt LW, Wingerden JV, Frequin S, Uitdehaag BMJ. Cost-minimization analysis of alemtuzumab compared to fingolimod and natalizumab for the treatment of active relapsing-remitting multiple sclerosis in the Netherlands. J Med Econ. 2018;21(10):968-76. https://doi.org/10.1080/13696998.2018.1489255.

27. Stanisic S, Bergamaschi R, Berto P, Di Procolo P, Marocco A, Morawski J. PND72-Cost-minimization analysis of teriflunomide and dimethyl fumarate for treatment of relapsing-remitting forms of multiple sclerosis in Italy. Value Health. 2018;21: S341. https://doi.org/10.1016/j.jval.2018.09.2038.

28. Canadian Agency for Drugs and Technologies in Health (CADTH). CADTH common drug review. Pharmacoeconomic review report for Peginterferon beta-1a (Plegridy-subcutaneous injection). 2015. https://www.cadth.ca/sites/default/files/cdr/ pharmacoeconomic/SR0440_Plegridy_PE_Report. pdf. Accessed 18 Jan 2021.

29. Scottish Medicine Consortium (SNC). Fingolimod, $0.5 \mathrm{mg}$, hard capsules (Gilenya ${ }^{\circledR}$ ). SMC No. (992/ 14). 2014. https://www.scottishmedicines.org.uk/ media/1734/fingolimod_gilenya_final_august_ 2014_amended_030914_for_website.pdf. Accessed 15 Dec 2020.

30. Scottish Medicine Consortium (SMC). Teriflunomide, $14 \mathrm{mg}$, film-coated tablets (Aubagio $\AA$ ). SMC No. (940/14). 2014. https://www.scottishmedicines. org.uk/media/2382/teriflunomide_aubagio_final_ january_2014_amended_030314_for_website.pdf. Accessed 19 Nov 2020.

31. Dee A, Hutchinson M, De La Harpe D. A budget impact analysis of natalizumab use in Ireland. Ir J Med Sci. 2012;181(2):199-204. https://doi.org/10. 1007/s11845-011-0773-6.

32. Holownia-Voloskova M, Ermolaeva T, Klabukova D, et al. PND56-Budget impact analysis of inclusion in the public financing ocrelizumab therapy for primary-progredient and highly active remitting forms of multiple scelerosis in the Russian federation. Value Health. 2019;22:S747. https://doi.org/ 10.1016/j.jval.2019.09.1826.
33. Ristun C, Bjørnstad B, Hestvik ALK, Myhr KM, Mikkelsen Y. PND43-Budget impact of the introduction of alemtuzumab in Norway; a real world evidence analysis using data from the Norwegian patient registry, the Norwegian prescription database, and IMS sales data. Value Health. 2019;22: S744. https://doi.org/10.1016/j.jval.2019.09.1813.

34. Londono S, Gomez N. PND19-Budget impact modelling for alemtuzumab in relapsing-remitting multiple sclerosis patients in Colombia. Value Health. 2020;23:S625. https://doi.org/10.1016/j. jval.2020.08.1344.

35. Moreno M, Arce J, Cruz A, Carpio FR. PND37Budget impact analysis of alemtuzumab in patients with relapsing-remitting multiple sclerosis in healthcare social security (ESSALUD) in Peru. Value Health. 2020;23:S265. https://doi.org/10.1016/j. jval.2020.04.930.

36. Bohlega SA, Al-Mudaiheem $\mathrm{H}$, Alhowimel $\mathrm{M}$, Mahajan K, Mohamed O, Boghdady AE. Budget impact analysis of cladribine tablets in relapsingremitting multiple sclerosis (RRMS) patients in Kingdom of Saudi Arabia. Mult Scler Relat Disord. 2020;37:101545. https://doi.org/10.1016/j.msard. 2019.11.020.

37. Bose U, Ladkani D, Burrell A, Sharief M. Cost-effectiveness analysis of glatiramer acetate in the treatment of relapsing-remitting multiple sclerosis. J Med Econ. 2001;4(1-4):207-19. https://doi.org/10. $3111 / 200104207219$.

38. Chiao E, Meyer K. Cost effectiveness and budget impact of natalizumab in patients with relapsing multiple sclerosis. Curr Med Res Opin. 2009;25(6): 1445-54. https://doi.org/10.1185/03007990902876 040 .

39. Metni M, Yamout B, Koussa S, Khamis C, Fleifel L, Sharifi S, et al. PND53-Economic evaluation of cladribine tablets in relapsing multiple sclerosis (RMS) patients with high disease activity (HDA) in Lebanon. Value Health. 2019;22:S746. https:/doi. org/10.1016/j.jval.2019.09.1823.

40. Noyes K, Bajorska A, Chappel A, et al. Cost-effectiveness of disease-modifying therapy for multiple sclerosis: a population-based study. Neurology. 2011;77(4):355-63. https://doi.org/10.1212/WNL. ob013e3182270402.

41. Pan F, Goh JW, Cutter G, Su W, Pleimes D, Wang C. Long-term cost-effectiveness model of interferon beta-1b in the early treatment of multiple sclerosis in the United States. Clin Ther. 2012;34(9):1966-76. https://doi.org/10.1016/j.clinthera.2012.07.010.

42. Ravangard R, Rezaee M, Keshavarz K, Borhanihaghighi A, Izadi S. Cost-effectiveness and cost- 
utility of CinnoVex versus ReciGen in patients with relapsing-remitting multiple sclerosis in Iran. Shiraz E-Med J. 2018;19(11): e67363. https://doi.org/10. 5812/semj.67363.

43. Rezaee M, Izadi S, Keshavarz K, Borhanihaghighi A, Ravangard R. Fingolimod versus natalizumab in patients with relapsing remitting multiple sclerosis: a cost-effectiveness and cost-utility study in Iran. J Med Econ. 2019;22(4):297-305. https://doi.org/ 10.1080/13696998.2018.1560750.

44. Djambazov S, Slavchev G, Dineva T, Panayotov P, Vekov T. Cost-effectiveness analysis of cladribine tablets for treatment of patients with relapsingremitting multiple sclerosis in Bulgaria. Value Health. 2018;21:S206. https://doi.org/10.1016/j. jval.2018.04.1403.

45. Harty G, Treharne C, Budhia S, Wong SL. PND28A budget impact analysis of cladribine tablets versus alternative high efficacy treatments for relapsing multiple sclerosis (RMS) in the United Kingdom. Value Health. 2018;21:S333. https://doi.org/10. 1016/j.jval.2018.09.1995.

46. Yang H, Duchesneau E, Foster R, Guerin A, Ma E, Thomas NP. Cost-effectiveness analysis of ocrelizumab versus subcutaneous interferon beta-1a for the treatment of relapsing multiple sclerosis. J Med Econ. 2017;20(10):1056-65. https://doi.org/10. 1080/13696998.2017.1355310.

47. Espinola N, Palacios A, Saenz V, et al. PND1-Costeffectiveness analysis of cladribine in high disease activity relapse remitting multiple sclerosis in Argentina. Value Health Reg Issues. 2019;19:S58. https://doi.org/10.1016/j.vhri.2019.08.331.

48. Espinoza MA, Balmaceda C, Rojas R. PND7-Costeffectiveness of cladribine compared to natalizumab, ocrelizumab and alemtuzumab for the treatment of patients with highly active relapsing remitting multiple sclerosis in Chile. Value Health Reg Issues. 2019;19:S60. https://doi.org/10.1016/j. vhri.2019.08.337.

49. Rog D, Guo JD, Nucit A, Le Bagousse-Bego G, Chevli M, Chung L. PND31-Alemtuzumab is the most cost-effective option in comparison to available therapies in the treatment of RRMS from the UK NHS perspective. Value Health. 2017;20:A723.

50. Sánchez-de la Rosa R, Sabater E, Casado MA, Arroyo R. Cost-effectiveness analysis of disease modifiying drugs (interferons and glatiramer acetate) as first line treatments in remitting-relapsing multiple sclerosis patients. J Med Econ. 2012;15(3):424-33. https://doi.org/10.3111/13696998.2012.654868.

51. Su W, Kansal A, Vicente C, Deniz B, Sarda S. The cost-effectiveness of delayed-release dimethyl fumarate for the treatment of relapsing-remitting multiple sclerosis in Canada. J Med Econ. 2016;19(7):718-27. https://doi.org/10.3111/ 13696998.2016.1164174.

52. Hammes F, Ruiz L, Gitlin M, Snyder S. PND34Payer and societal benefit of peginterferon beta-1a versus glatiramer acetate in patients with relapsingremitting multiple sclerosis in Spain. Value Health. 2018;21:S334-5. https://doi.org/10.1016/j.jval. 2018.09.2001.

53. Hammes F, Wakeford C, Gitlin M, Snyder S. PND33-Payer and societal benefit of peginterferon beta-1a versus glatiramer acetate in patients with relapsing-remitting multiple sclerosis in Italy. Value Health. 2018;21:S334. https://doi.org/10.1016/j. jval.2018.09.2000.

54. Watson C, Gitlin M, Snyder S. PND26-Cost consequence analysis of SC peginterferon beta-1a every 2 weeks versus SC interferon beta-1atiw in patients with RRMS in five European countries. Value Health. 2017;20:A192.

55. Watson C, Gitlin M, Snyder S. PND27-Cost consequence analysis of SC peginterferon beta-1a every 2 weeks versus SC interferon beta-1atiw in patients with RRMS in the United States. Value Health. 2017;20(5):A192. https://doi.org/10.1016/j.jval. 2017.05.005.

56. Bosco-Levy P, Blin P, Lignot-Maleyran S, et al. PND25-Cost-consequence analysis of dimethyl fumarate versus other disease-modifying therapies in multiple sclerosis: a French cohort study with SNDS national claims database in France. Value Health. 2020;23:S626. https://doi.org/10.1016/j. jval.2020.08.1350.

57. Silverio N, Fonseca A. PND26-Cost implications of a novel weight dosed treatment for highly active relapsing multiple sclerosis in Portugal. Value Health. 2018;21:S333. https://doi.org/10.1016/j. jval.2018.09.1994.

58. Gitlin M, Snyder S, Jhaveri M. PND40-Payer and societal benefit of peginterferon beta-1a versus subcutaneous interferon beta-1a in patients with relapsing-remitting multiple sclerosis in Spain. Value Health. 2019;22:S744. https://doi.org/10. 1016/j.jval.2019.09.1810.

59. Gitlin M, Snyder S, Jhaveri M. PND52-Payer and societal benefit of peginterferon beta-1a versus subcutaneous interferon beta-1a in patients with relapsing-remitting multiple sclerosis in Italy. Value Health. 2019;22:S746. https://doi.org/10.1016/j. jval.2019.09.1822.

60. Mennini FS, Marcellusi A, Casamassima G. PND76-The economic consequences of benefits of 
delayed-release dimethyl fumarate treatment versus beta interferons and glatiramer acetate on ability to work of multiple sclerosis patients in Italy. Value Health. 2018;21:S341-2. https://doi.org/10.1016/j. jval.2018.09.2042.

61. Thomas N, Ma E, Yu EB. PND23-Economic implications of replacing interferon beta-1a with ocrelizumab in relapsing multiple sclerosis. Value Health. 2017;20(5):A191. https://doi.org/10.1016/j. jval.2017.05.005.

62. Brown MG, Murray TJ, Sketris IS, Fisk JD, LeBlanc JC, Schwartz CE, et al. Cost-effectiveness of interferon beta-1b in slowing multiple sclerosis disability progression. First estimates. Int $\mathrm{J}$ Technol Assess Health Care. 2000;16(3):751-67. https://doi.org/10. 1017/s026646230010203x.

63. Chilcott J, McCabe C, Tappenden P, et al. Modelling the cost effectiveness of interferon beta and glatiramer acetate in the management of multiple sclerosis. Commentary: evaluating disease modifying treatments in multiple sclerosis. BMJ. 2003;326(7388):522. https://doi.org/10.1136/bmj. 326.7388 .522 .

64. Janković SM, Kostić M, Radosavljević M, et al. Costeffectiveness of four immunomodulatory therapies for relapsing-remitting multiple sclerosis: a Markov model based on data a Balkan country in socioeconomic transition. Vojnosanit Pregl. 2009;66(7): 556-62. https://doi.org/10.2298/vsp0907556j.

65. Parkin D, McNamee P, Jacoby A, Miller P, Thomas S, Bates D. A cost-utility analysis of interferon beta for multiple sclerosis. Health Technol Assess. 1998;2(4): iii-54.

66. Tappenden P, McCabe C, Chilcott J, et al. Cost-effectiveness of disease-modifying therapies in the management of multiple sclerosis for the Medicare population. Value Health. 2009;12(5):657-65. https://doi.org/10.1111/j.1524-4733.2008.00485.x.

67. Zimmermann M, Brouwer E, Tice JA,et al. Diseasemodifying therapies for relapsing-remitting and primary progressive multiple sclerosis: a cost-utility analysis. CNS Drugs. 2018;32(12):1145-57. https:// doi.org/10.1007/s40263-018-0566-9.

68. Chanatittarat C, Chaikledkaew U, Prayoonwiwat N, et al. Cost-utility analysis of multiple sclerosis treatment in Thailand. Int J Technol Assess Health Care. 2018. https://doi.org/10.1017/s0266462318 003604.

69. Dashputre AA, Kamal KM, Pawar G. Cost-effectiveness of peginterferon beta-1a and alemtuzumab in relapsing-remitting multiple sclerosis. J Manag Care Spec Pharm. 2017;23(6):666-76. https://doi.org/10. 18553/jmcp.2017.23.6.666.
70. Forbes RB, Lees A, Waugh N, Swingler RJ. Population based cost utility study of interferon beta-1b in secondary progressive multiple sclerosis. Br Med J (Clin Res Ed). 1999;319(7224):1529-33. https://doi. org/10.1136/bmj.319.7224.1529.

71. Lee S, Baxter DC, Limone B, Roberts MS, Coleman CI. Cost-effectiveness of fingolimod versus interferon beta-1a for relapsing remitting multiple sclerosis in the United States. J Med Econ. 2012;15(6): 1088-96. https://doi.org/10.3111/13696998.2012. 693553.

72. Sawad AB, Seoane-Vazquez E, Rodriguez-Monguio R, Turkistani F. Cost-effectiveness of different strategies for treatment relapsing-remitting multiple sclerosis. J Comp Eff Res. 2017;6(2):97-108. https://doi.org/10.2217/cer-2016-0056.

73. Zhang X, Hay JW, Niu X. Cost effectiveness of fingolimod, teriflunomide, dimethyl fumarate and intramuscular interferon- $\beta 1 \mathrm{a}$ in relapsing-remitting multiple sclerosis. CNS Drugs. 2015;29(1):71-81. https://doi.org/10.1007/s40263-014-0207-x.

74. Kremer IEH, Hiligsmann M, Carlson J, et al. Exploring the cost effectiveness of shared decision making for choosing between disease-modifying drugs for relapsing-remitting multiple sclerosis in The Netherlands: a state transition model. Med Decis Making. 2020;40(8):1003-19. https://doi.org/ $10.1177 / 0272989 \times 20961091$.

75. Darbà J, Kaskens L, Sánchez-de la Rosa R. Cost-effectiveness of glatiramer acetate and interferon beta-1a for relapsing-remitting multiple sclerosis, based on the CombiRx study. J Med Econ. 2014;17(3):215-22. https://doi.org/10.3111/ 13696998.2014 .890936$.

76. Dembek C, White LA, Quach J, Szkurhan A, Rashid N, Blasco MR. Cost-effectiveness of injectable disease-modifying therapies for the treatment of relapsing forms of multiple sclerosis in Spain. Eur J Health Econ. 2014;15(4):353-62. https://doi.org/10. 1007/s10198-013-0478-z.

77. Herring W, Gould IG, Ruiz L, Dort T, Zhang Y, Acosta C, et al. PND56-A cost-effectiveness analysis using real-world data from the MSBase registry: comparing natalizumab to fingolimod in patients with inadequate response to disease-modifying therapies in relapsing-remitting multiple sclerosis in Spain. Value Health. 2018;21:S338. https://doi. org/10.1016/j.jval.2018.09.2022.

78. Poveda JL, Trillo JL, Rubio-Terrés C, Rubio-Rodríguez D, Polanco A, Torres C. Cost-effectiveness of cladribine tablets and fingolimod in the treatment of relapsing multiple sclerosis with high disease activity in Spain. Expert Rev Pharmacoecon 
Outcomes Res. 2019. https://doi.org/10.1080/ 14737167.2019.1635014.

79. Ruiz L, Machado M, Toro-Diaz H, Cele C, Hernandez L, Harrington A. PND39-Cost effectiveness analysis of dimethyl fumarate versus teriflunomide for the treatment of multiple sclerosis. Value Health. 2017;20(9):A724. https://doi.org/10.1016/j. jval.2017.08.1952.

80. Ruiz L, Toro-Diaz H, Cele C, Hernandez L, Harrington A. PND35-Cost-effectiveness analysis of peginterferon beta-1a vs. first-line injectable disease-modifying therapies for the treatment of relapsing-remitting multiple sclerosis in Spain. Value Health. 2017;20(9):A723. https://doi.org/10. 1016/j.jval.2017.08.1948.

81. Scottish Medicine Consortium (SMC). Natalizumab 300mg concentrate for solution for infusion (Tysabri ${ }^{\circledR}$ ) (No. 329/06). 2006. https://www. scottishmedicines.org.uk/medicines-advice/ natalizumab-300mg-concentrate-for-solution-forinfusion-tysabri-fullsubmission-32906/. Accessed 19 Nov 2020.

82. Scottish Medicine Consortium (SMC). Resubmission natalizumab $300 \mathrm{mg}$ concentrate for solution for infusion (Tysabri $\left.{ }^{\circledR}\right)$ No. (329/06). 2007. https:// www.scottishmedicines.org.uk/media/2028/ natalizumab_300mg_concentrate_for_solution_for_ infusion_tysabri_resubmission_final_august_ 2007_for_website.pdf. Accessed 13 Jan 2021.

83. Scottish Medicine Consortium (SMC). Dimethyl fumarate $120 \mathrm{mg}, 240 \mathrm{mg}$ gastro-resistant hard capsules (Tecfidera $\left.{ }^{\circledR}\right)$ SMC No. (886/13). 2013. https:// www.scottishmedicines.org.uk/media/1570/ dimethyl_fumarate_tecifidera_final_july_2013_ amended_030414_for_website.pdf. Accessed 19 Nov 2020 .

84. Scottish Medicine Consortium (SMC). Resubmission fingolimod (as hydrochloride), $0.5 \mathrm{mg}$ hard capsules (Gilenya $\left.{ }^{\circledR}\right)$ SMC No. (763/12). 2012. https://www.scottishmedicines.org.uk/media/1733/ fingolimod_gilenya_resubmission_final_august_ 2012_amended_300812.pdf. Accessed 19 Nov 2020.

85. Scottish Medicine Consortium (SMC). Peginterferon-beta-1a 63, 94 and 125 microgram solution for injection in pre-filled syringe (Plegridy $\left.{ }^{\circledR}\right)$ SMC No. (1018/14). 2014. https://www.scottishmedicin es.org.uk/media/2127/peginterferon_beta_1a plegridy_final_dec_2014_for_website.pdf. Accessed 19 Nov 2020.

86. Scottish Medicine Consortium. Alemtuzumab, $12 \mathrm{mg}$, concentrate for solution for infusion (Lemtrada $\left.{ }^{\circledR}\right)$ SMC No. (959/14). 2014. https://www. scottishmedicines.org.uk/media/1224/ alemtuzumab_lemtrada_final_april_2014_ amended_240414_020714_for_website.pdf. Accessed 19 Nov 2020.

87. Scottish Medicine Consortium (SMC). Fingolimod $0.5 \mathrm{mg}$ hard capsules (Gilenya ${ }^{\circledR}$ ) SMC No. (1038/ 15). 2015. https://www.scottishmedicines.org.uk/ media/1732/fingolimod_gilenya_final_march_ 2015_amended_070415_for_website.pdf. Accessed 19 Nov 2020.

88. Scottish Medicine Consortium (SMC). Cladribine $10 \mathrm{mg}$ tablet (Mavenclad $\AA$ ) SMC No (1300/18). 2018. https://www.scottishmedicines.org.uk/ media/3097/cladribine_mavenclad_final_jan_2018_ amended_070218_for_website.pdf. Accessed 19 Nov 2020 .

89. Scottish Medicine Consortium (SMC). Ocrelizumab $300 \mathrm{mg}$ concentrate for solution for infusion (Ocrevus () . 2018. https://www.scottishmedicines.org. uk/media/3966/ocrelizumab-ocrevus-rrms-resubfinal-nov-2018-amended-051218-for-website.pdf. Accessed 19 Nov 2020.

90. National Institute for Health and Care Excellence (NICE). Natalizumab for the treatment of adults with highly active relapsing-remitting multiple sclerosis (TA127). NICE; 2007. https://www.nice. org.uk/guidance/ta127. Accessed 19 Nov 2020.

91. National Institute for Health and Care Excellence (NICE). Fingolimod for the treatment of highly active relapsing-remitting multiple sclerosis (TA254). NICE; 2012. https://www.nice.org.uk/ guidance/ta254/documents/manufacturersubmission-from-novartis2. Accessed 19 Nov 2020.

92. National Institute for Health and Care Excellence (NICE). Dimethyl fumarate for treating relapsingremitting multiple sclerosis. NICE; 2013. https:// www.nice.org.uk/guidance/ta320/documents/ multiple-sclerosis-relapsingremitting-dimethylfumarate-evaluation-report2. Accessed 19 Nov 2020.

93. National Institute for Health and Care Excellence (NICE). Alemtuzumab for treating relapsing-remitting multiple sclerosis (TA312). NICE; 2014. https:// www.nice.org.uk/guidance/ta312. Accessed 19 Nov 2020.

94. National Institute for Health and Care Excellence (NICE). Teriflunomide for treating relapsing-remitting multiple sclerosis (TA303). NICE; 2014. https:// www.nice.org.uk/guidance/ta303. Accessed 19 Nov 2020 .

95. National Institute for Health and Care Excellence (NICE). Beta interferon and glatiramer acetate for the treatment of multiple sclerosis (TA527). NICE; 2018. https://www.nice.org.uk/guidance/TA527. Accessed 19 Nov 2020. 
96. National Institute for Health and Care Excellence (NICE). Ocrelizumab for treating relapsing multiple sclerosis. NICE; 2018. https://www.nice.org.uk/ guidance/ta533/documents/committee-papers. Accessed 18 Jan 2021.

97. National Institute for Health and Care Excellence (NICE). Cladribine for treating relapsing-remitting multiple sclerosis technology appraisal guidance (TA616). NICE; 2019. https://www.nice.org.uk/ guidance/ta616. Accessed 19 Nov 2020.

98. Canadian Agency for Drugs \& Technologies in Health (CADTH). CADTH therapeutic review. Comparative clinical and cost-effectiveness of drug therapies for relapsing-remitting multiple sclerosis. 2013. https://www.cadth.ca/media/pdf/TR0004 RRMS_ScienceReport_e.pdf. Accessed 19 Nov 2020.

99. Canadian Agency for Drugs \& Technologies in Health (CADTH). CADTH common drug review. Pharmacoeconomic review report for teriflunomide (Aubagio) (14 mg film-coated tablet). 2014. https:// www.cadth.ca/sites/default/files/cdr/

pharmacoeconomic/SR0350_Aubagio_PE_Report_e. pdf. Accessed 19 Nov 2020.

100. Canadian Agency for Drugs \& Technologies in Health (CADTH). CADTH common drug review. Pharmacoeconomic review report for alemtuzumab (Lemtrada, intravenous). 2014. https://www.cadth. $\mathrm{ca} /$ sites/default/files/cdr/pharmacoeconomic/ SR0405_Lemtrada_RRMS_PE_Report.pdf. Accessed 19 Nov 2020.

101. Canadian Agency for Drugs \& Technologies in Health (CADTH). CADTH common drug review. Pharmacoeconomic review report Ocrelizumab (Ocrevus) version 1.0. 2017. https://www.cadth.ca/ sites/default/files/cdr/pharmacoeconomic/SR0519_ Ocrevus_RMS\%20_PE_Report.pdf. Accessed 19 Nov 2020.

102. Canadian Agency for Drugs \& Technologies in Health (CADTH). CADTH common drug review. Pharmacoeconomic review report for daclizumab (Zinbryta). 2017. https://www.cadth.ca/sites/ default/files/cdr/pharmacoeconomic/SR0508_ Zinbryta_PE_Report.pdf. Accessed 19 Nov 2020.

103. Canadian Agency for Drugs \& Technologies in Health (CADTH). CADTH common drug review. Pharmacoeconomic review report for cladribine (Mavenclad). 2018. https://www.cadth.ca/sites/ default/files/cdr/pharmacoeconomic/SR0546 Mavenclad_PE_Report.pdf. Accessed 19 Nov 2020.

104. Agashivala N, Kim E. Cost-effectiveness of early initiation of fingolimod versus delayed initiation after 1 year of intramuscular interferon beta-1a in patients with multiple sclerosis. Clin Ther.
2012;34(7):1583-90.

https://doi.org/10.1016/j. clinthera.2012.06.012.

105. Brandes DW, Raimundo K, Agashivala N, Kim E. Implications of real-world adherence on cost-effectiveness analysis in multiple sclerosis. J Med Econ. 2013;16(4):547-51. 13696998.2013 .774281$.

106. Goldberg LD, Edwards NC, Fincher C, Doan QV, AlSabbagh A, Meletiche DM. Comparing the cost-effectiveness of disease-modifying drugs for the firstline treatment of relapsing-remitting multiple sclerosis. J Manag Care Pharm. 2009;15(7):543-55. https://doi.org/10.18553/jmcp.2009.15.7.543.

107. Nuijten M, Mittendorf T. A health-economic evaluation of disease-modifying drugs for the treatment of relapsing-remitting multiple sclerosis from the German societal perspective. Clin Ther. 2010;32(4): 717-28. https://doi.org/10.1016/j.clinthera.2010. 03.019.

108. O’Day K, Meyer K, Miller RM, Agarwal S, Franklin $M$. Cost-effectiveness of natalizumab versus fingolimod for the treatment of relapsing multiple sclerosis. J Med Econ. 2011;14(5):617-27. https:// doi.org/10.3111/13696998.2011.602444.

109. O'Day K, Meyer K, Stafkey-Mailey D, Watson C. Cost-effectiveness of natalizumab vs fingolimod for the treatment of relapsing-remitting multiple sclerosis: analyses in Sweden. J Med Econ. 2015;18(4): 295-302. https://doi.org/10.3111/13696998.2014. 991786.

110. All Wales Therapeutics and Toxicology Centre. AWMSG Secretariat Assessment Report. Fingolimod (Gilenya $\left.{ }^{\circledR}\right) 0.5 \mathrm{mg}$ hard capsules. Reference number: 3135. 2016. https://awmsg.nhs.wales/files/ appraisals-asar-far/appraisal-report-fingolimodgilenya-3135/. Accessed 19 Nov 2020.

111. Guo S, Bozkaya D, Ward A, et al. Treating relapsing multiple sclerosis with subcutaneous versus intramuscular interferon-beta-1a: modelling the clinical and economic implications. Pharmacoeconomics. 2009;27(1):39-53. 00019053-200927010-00005.

112. Montgomery SM, Kusel J, Nicholas R, Adlard N. Costs and effectiveness of fingolimod versus alemtuzumab in the treatment of highly active relapsing-remitting multiple sclerosis in the UK: retreatment, discount, and disutility. J Med Econ. 2017;20(9):962-73. https://doi.org/10.1080/ 13696998.2017.1345748.

113. Montgomery SM, Maruszczak MJ, Slater D, Kusel J, Nicholas R, Adlard N. A discrete event simulation to model the cost-utility of fingolimod and natalizumab in rapidly evolving severe relapsing- 
remitting multiple sclerosis in the UK. J Med Econ. 2017;20(5):474-82. https://doi.org/10.1080/ 13696998.2016.1276070.

114. Brett McQueen R, Nair KV, Vollmer TL, Campbell JD. Incorporating real-world clinical practice in multiple sclerosis economic evaluations. Expert Rev Pharmacoecon Outcomes Res. 2015;15(6):869-72. https://doi.org/10.1586/14737167.2015.1081060.

115. Silverio N, Fonseca A. PND65-Cost-effectiveness analysis of drugs used for the treatment of highly active relapsing multiple sclerosis in Portugal. Value Health. 2018;21:S340. https://doi.org/10.1016/j. jval.2018.09.2031.

116. Rosim R, Rigolon J, Fahham L. PND3-Cost-utility analysis of natalizumab as first line therapy for highly active relapsing-remitting multiple sclerosis from a Brazilian private payer perspective. Value Health Reg Issues. 2019;19:S59. https://doi.org/10. 1016/j.vhri.2019.08.333.

117. Brennan A, Chick SE, Davies R. A taxonomy of model structures for economic evaluation of health technologies. Health Econ. 2006;15(12):1295-310. https://doi.org/10.1002/hec.1148.

118. Salleh S, Thokala P, Brennan A, Hughes R, Booth A. Simulation modelling in healthcare: an umbrella review of systematic literature reviews. Pharmacoeconomics. 2017;35(9):937-49. https://doi.org/ 10.1007/s40273-017-0523-3.

119. Chirikov V, Ma I, Joshi N, et al. Cost-effectiveness of alemtuzumab in the treatment of relapsing forms of multiple sclerosis in the United States. Value Health. 2019;22(2):168-76. https://doi.org/10. 1016/j.jval.2018.08.011.

120. Frasco MA, Shih T, Incerti D, Diaz Espinosa O, Vania $\mathrm{DK}$, Thomas N. Incremental net monetary benefit of ocrelizumab relative to subcutaneous interferon $\beta$-1a. J Med Econ. 2017;20(10):1074-82. https://doi. org/10.1080/13696998.2017.1357564.

121. Hettle R, Harty G, Wong SL. Cost-effectiveness of cladribine tablets, alemtuzumab, and natalizumab in the treatment of relapsing-remitting multiple sclerosis with high disease activity in England. J Med Econ. 2018;21(7):676-86. https://doi.org/10. 1080/13696998.2018.1461630.

122. Rock M, Dort T, Snyder S, Gitlin M. PND18-Clinical and economic impact of initiating dimethyl fumarate versus other disease modyfing therapies in patients with relapsing remitting multiple sclerosis in Germany. Value Health. 2019;22:S273. https:// doi.org/10.1016/j.jval.2019.04.1292.

123. Rock M, Rosim RP, Rigolon J, Dort T, Snyder S, Gitlin M. PND11-Economic impact of initiating dimethyl fumarate versus other disease modifying therapies in publicly insured Brazilian patients with relapsing-remitting multiple sclerosis. Value Health Reg Issues. 2019;19:S61.

124. Xu Y, Mao N, Chirikov V, et al. Cost-effectiveness of teriflunomide compared to interferon beta- $1 \mathrm{~b}$ for relapsing multiple sclerosis patients in China. Clin Drug Investig. 2019;39(3):331-40. https://doi.org/ 10.1007/s40261-019-00750-3.

125. Gaitova K, Tamabekov Y. PND7-cost-effectiveness of cladribine tablets in the treatment of relapsingremitting multiple sclerosis with high disease activity in Kazakhstan. Value Health Reg Issues. 2020;22:S75. https://doi.org/10.1016/j.vhri.2020. 07.395 .

126. School of Health and Related Research (ScHARR). Cost effectiveness of beta interferons and glatiramer acetate in the management of multiple sclerosis. Sheffield: School of Health and Related Research; 2001. https://www.nice.org.uk/guidance/ta32/ documents/assessment-report-on-the-use-of-betainterferon-and-glatiramer-acetate-for-multiplesclerosis-scharr-report2. Accessed 19 Nov 2020.

127. National Institute for Health and Care Excellence (NICE). The effectiveness and cost-effectiveness of natalizumab for multiple sclerosis: an evidence review of the submission from biogen. NICE; 2007. https://www.nice.org.uk/guidance/ta127/ documents/multiple-sclerosis-natalizumabevaluation-report-evidence-review-group-report2. Accessed 19 Nov 2020.

128. Gani R, Giovannoni G, Bates D, Kemball B, Hughes $\mathrm{S}$, Kerrigan J. Cost-effectiveness analyses of natalizumab (Tysabri) compared with other diseasemodifying therapies for people with highly active relapsing-remitting multiple sclerosis in the UK. Pharmacoeconomics. 2008;26(7):617-27. https:// doi.org/10.2165/00019053-200826070-00008.

129. Henriksson F, Fredrikson S, Masterman T, Jönsson B. Costs, quality of life and disease severity in multiple sclerosis: a cross-sectional study in Sweden. Eur J Neurol. 2001;8(1):27-35. https://doi.org/ 10.1046/j.1468-1331.2001.00169.x.

130. Kobelt G, Jönsson L, Fredrikson S. Cost-utility of interferon beta in the treatment of patients with active relapsing-remitting or secondary progressive multiple sclerosis. Eur J Health Econ. 2003;4(1): 50-9.

131. Kobelt G, Lindgren P, Smala A, et al. Costs and quality of life in multiple sclerosis: an observational study in Germany. Eur J Health Econ. 2001;2(2): 60-8. 
132. Kobelt G, Jönsson L, Henriksson F, Fredrikson S, Jönsson B. Cost-utility analysis of interferon beta-1b in secondary progressive multiple sclerosis. Int $\mathrm{J}$ Technol Assess Health Care. 2000;16(03):768-80. https://doi.org/10.1017/S0266462300102041.

133. Palace J, Bregenzer T, Tremlett H, Oger J, Zhu F, Boggild $\mathrm{M}$, et al. UK multiple sclerosis risk-sharing scheme: a new natural history dataset and an improved Markov model. BMJ Open. 2014;4(1): e004073. https://doi.org/10.1136/bmjopen-2013004073.

134. Kobelt G, Lindgren P, Parkin D, Francis DA, Johnson $\mathrm{M}$, Bates $\mathrm{D}$ et al. Costs and quality of life in multiple sclerosis. A cross-sectional observational study in the UK. 2000. https://ideas.repec.org/p/hhs/hastef/ 0398.html. Accessed 19 Nov 2020.

135. Prosser LA, Kuntz KM, Bar-Or A, Weinstein MC. Cost-effectiveness of interferon beta-1a, interferon beta- $1 b$, and glatiramer acetate in newly diagnosed non-primary progressive multiple sclerosis. Value Health. 2004;7(5):554-68. https://doi.org/10.1111/ j.1524-4733.2004.75007.x.

136. Ebers GC, Koopman WJ, Hader W, et al. The natural history of multiple sclerosis: a geographically based study: 8: familial multiple sclerosis. Brain. 2000;123(3):641-9. https://doi.org/10.1093/brain/ 123.3.641.

137. Bell C, Graham J, Earnshaw S, Oleen-Burkey M, Castelli-Haley J, Johnson K. Cost-effectiveness of four immunomodulatory therapies for relapsingremitting multiple sclerosis: a Markov model based on long-term clinical data. J Manag Care Pharm. 2007;13(3):245-61. https://doi.org/10.18553/jmcp. 2007.13.3.245.

138. Hashemi-Meshkini A, Zekri HS, Karimi-Yazdi H, Zaboli P, Sahraian MA, Nikfar S. Pegylated versus non-pegylated interferon beta $1 \mathrm{a}$ in patients with relapsing-remitting multiple sclerosis: a cost-effectiveness analysis. Iran J Neurol. 2018;17(3):123-8.

139. Bozkaya D, Livingston T, Migliaccio-Walle K, Odom $\mathrm{T}$. The cost-effectiveness of disease-modifying therapies for the treatment of relapsing-remitting multiple sclerosis. J Med Econ. 2017;20(3):297-302. https://doi.org/10.1080/13696998.2016.1258366.

140. Chevalier J, Chamoux C, Hammès F, Chicoye A. Cost-effectiveness of treatments for relapsing remitting multiple sclerosis: a French societal perspective. PLoS ONE. 2016;11(3): e0150703. https:// doi.org/10.1371/journal.pone.0150703.

141. Hernandez L, Guo S, Kinter E, Fay M. Cost-effectiveness analysis of peginterferon beta-1a compared with interferon beta-1a and glatiramer acetate in the treatment of relapsing-remitting multiple sclerosis in the United States. J Med Econ. 2016;19(7):684-95. https://doi.org/10.3111/ 13696998.2016.1157080.

142. Kobelt G, Jönsson L, Miltenburger C, Jönsson B. Cost-utility analysis of interferon beta-1B in secondary progressive multiple sclerosis using natural history disease data. Int $\mathrm{J}$ Technol Assess Health Care. 2002;18(1):127-38.

143. Mauskopf J, Fay M, Iyer R, Sarda S, Livingston T. Cost-effectiveness of delayed-release dimethyl fumarate for the treatment of relapsing forms of multiple sclerosis in the United States. J Med Econ. 2016;19(4):432-42. https://doi.org/10.3111/ 13696998.2015.1135805.

144. Taheri S, Sahraian MA, Yousefi N. Cost-effectiveness of alemtuzumab and natalizumab for relapsingremitting multiple sclerosis treatment in Iran: decision analysis based on an indirect comparison. J Med Econ. 2019;22(1):71-84. https://doi.org/10. 1080/13696998.2018.1543189.

145. Walter E, Berger T, Bajer-Kornek B, Deisenhammer F. Cost-utility analysis of alemtuzumab in comparison with interferon beta, fingolimod, and natalizumab treatment for relapsing-remitting multiple sclerosis in Austria. J Med Econ. 2019;22(3):226-37. https://doi.org/10.1080/13696998.2018.1556668.

146. Phillips CJ, Gilmour L, Gale R, Palmer M. A cost utility model of interferon beta- $1 \mathrm{~b}$ in the treatment of relapsing-remitting multiple sclerosis. J Med Econ. 2001;4(1-4):35-50. https://doi.org/10.3111/ 200104035050.

147. Centonze D, Iannazzo S, Santoni L, et al. The economic profile of peginterferon beta-1a in the treatment of relapsing-remitting multiple sclerosis in Italy. Mult Scler Demyelinating Disord. 2017;2(1): 13. https://doi.org/10.1186/s40893-017-0030-6.

148. Smith A, Hashemi L, Wandstrat T. PND34-Costutility analysis of alemtuzumab versus subcutaneous interferon beta- $1 \mathrm{a}$ for the treatment of relapsing-remitting multiple sclerosis: US payer perspective. Value Health. 2017;20(5):A193. https:// doi.org/10.1016/j.jval.2017.05.005.

149. Touchette DR, Durgin TL, Wanke LA, Goodkin DE. A cost-utility analysis of mitoxantrone hydrochloride and interferon beta- $1 \mathrm{~b}$ in the treatment of patients with secondary progressive or progressive relapsing multiple sclerosis. Clin Ther. 2003;25(2): 611-34. 2918(03)80100-5.

150. Lasalvia P, Hernández F, Castañeda-Cardona C, Cuestas JA, Rosselli D. Cost-effectiveness of natalizumab compared with fingolimod for relapsingremitting multiple sclerosis treatment in Colombia. 
Value Health Reg Issues. 2020;23:13-8. https://doi. org/10.1016/j.vhri.2019.08.481.

151. Giovannoni G, Brex PA, Dhiraj D, et al. Glatiramer acetate as a clinically and cost-effective treatment of relapsing multiple sclerosis over 10 years of use within the National Health Service: final results from the UK Risk Sharing Scheme. Mult Scler J Exp Transl Clin. 2019;5(4):2055217319893103. https:// doi.org/10.1177/2055217319893103.

152. Nikfar S, Kebriaeezadeh A, Dinarvand R, et al. Costeffectiveness of different interferon beta products for relapsing-remitting and secondary progressive multiple sclerosis: Decision analysis based on longterm clinical data and switchable treatments. Daru. 2013;21(1):50. https://doi.org/10.1186/2008-223121-50.

153. Phelps H, Treharne C, Ramirez Guevara G, Bertranou E. PND73-The impact of modelling subsequent treatment on estimates of cost-effectiveness: an analysis of disease-modifying treatments for relapsing-remitting multiple sclerosis in the United Kingdom. Value Health. 2018;21:S341. https://doi. org/10.1016/j.jval.2018.09.2039.

154. Pinheiro BA, Guerreiro R, Costa J, Silva ML. PND62-Cost-effectiveness of cladribine tablets in the treatment of patients with highly active relapsing multiple sclerosis in Portugal. Value Health. 2018;21:S339.

155. Earnshaw SR, Graham J, Oleen-Burkey M, CastelliHaley J, Johnson K. Cost effectiveness of glatiramer acetate and natalizumab in relapsing-remitting multiple sclerosis. Appl Health Econ Health Policy. 2009;7(2):91-108. https://doi.org/10.1007/bf0325 6144 .

156. Imani A, Golestani M. Cost-utility analysis of disease-modifying drugs in relapsing-remitting multiple sclerosis in Iran. Iran J Neurol. 2012;11(3): 87-90.

157. Furneri G, Santoni L, Ricella C, Prosperini L. Costeffectiveness analysis of escalating to natalizumab or switching among immunomodulators in relapsing-remitting multiple sclerosis in Italy. BMC Health Serv Res. 2019;19(1):436. https://doi.org/10. 1186/s12913-019-4264-1.

158. Soini E, Joutseno J, Sumelahti ML. Cost-utility of first-line disease-modifying treatments for relapsing-remitting multiple sclerosis. Clin Ther. 2017;39(3):537-57.e10. https://doi.org/10.1016/j. clinthera.2017.01.028.

159. All Wales Therapeutics and Toxicology Centre. AWMSG Secretariat Assessment Report. Peginterferon beta-1a (Plegridy®) 63 micrograms, 94 micrograms and 125 micrograms solution for injection in pre-filled pen. Reference number: 2013. 2015. http://www.awmsg.org/awmsgonline/app/ appraisalinfo/2013. Accessed 19 Nov 2020.

160. Haute Autorité de Santé. Tecfidera ${ }^{\circledR}$ (dimethyl fumarate) efficacy opinion. 2014. https://www.hassante.fr/jcms/c_1743058/fr/tecfidera-dimethylfumarate-traitement-de-fond-de-la-sclerose-enplaques. Accessed 19 Nov 2020.

161. Couto E, Hamidi V, Ringerike T, Odgaard-Jensen J, Harboe I, Klemp M. Medicines used for multiple sclerosis: a Health Technology Assessment. Report from Norwegian Institute of Public Health. Oslo: Norwegian Institute of Public Health; 2016.

162. Institute for Clinical and Economic Review. Disease-modifying therapies for relapsing-remitting and primary-progressive multiple sclerosis: effectiveness and value. 2017. http://icerorg.wpengine. com/wp-content/uploads/2020/10/CTAF_MS_

Final_Report_030617.pdf. Accessed 19 Nov 2020.

163. Alsaqa'aby MF, Vaidya V, Khreis N, Khairallah TA, Al-Jedai AH. Cost-effectiveness of oral agents in relapsing-remitting multiple sclerosis compared to interferon-based therapy in Saudi Arabia. Ann Saudi Med. 2017;37(6):433-43. https://doi.org/10.5144/ 0256-4947.2017.433.

164. Djambazov S, Vekov T. PND31-Cost-effectiveness analysis of alemtuzumab for the treatment of multiple sclerosis in Bulgaria, 2016. Value Health. 2017;20(5):A193.

165. Hua LH, Hersh CM, Morten P, et al. The impact of price reductions after loss of exclusivity in a costeffectiveness analysis: fingolimod versus interferon beta-1a for the treatment of relapsing-remitting multiple sclerosis. J Manag Care Spec Pharm. 2019;25(4):490-8. https://doi.org/10.18553/jmcp. 2019.25.4.490.

166. Maruszczak MJ, Montgomery SM, Griffiths MJS, Bergvall N, Adlard N. Cost-utility of fingolimod compared with dimethyl fumarate in highly active relapsing-remitting multiple sclerosis (RRMS) in England. J Med Econ. 2015;18(11):874-85. https:// doi.org/10.3111/13696998.2015.1056794.

167. Michels RE, de Fransesco M, Mahajan K, et al. Cost effectiveness of cladribine tablets for the treatment of relapsing-remitting multiple sclerosis in the Netherlands. Appl Health Econ Health Policy. 2019;17(6):857-73. https://doi.org/10.1007/ s40258-019-00500-8.

168. Ayati N, Sahraian MA, Taheri S, Nikfar S. PND45Ocrelizumab is a cost-effective option for relapsing multiple sclerosis patients, in Iran. Value Health. 2019;22:S744-5. https://doi.org/10.1016/j.jval. 2019.09.1815. 
169. Nuijten MJC, Hutton J. Cost-effectiveness analysis of interferon beta in multiple sclerosis: a markov process analysis. Value Health. 2002;5(1):44-54. https://doi.org/10.1046/j.1524-4733.2002.51052.x.

170. Kobelt G, Berg J, Lindgren P, Jonsson B, Stawiarz L, Hillert J. Modeling the cost-effectiveness of a new treatment for MS (natalizumab) compared with current standard practice in Sweden. Mult Scler. 2008;14(5):679-90. https://doi.org/10.1177/13524 58507086667.

171. Kourkoulas N, Athanasakis K, Theodorou M, Kyriopoulos J. PND66-Cost effectiveness analysis of alemtuzumab as a treatment option for patients with multiple sclerosis in Cyprus. Value Health. 2018;21:S340. https://doi.org/10.1016/j.jval.2018. 09.2032 .

172. Orme M, Kerrigan J, Tyas D, Russell N, Nixon R. The effect of disease, functional status, and relapses on the utility of people with multiple sclerosis in the UK. Value Health. 2007;10(1):54-60. https://doi. org/10.1111/j.1524-4733.2006.00144.x.

173. Prosser LA, Kuntz KM, Bar-Or A, Weinstein MC. Patient and community preferences for treatments and health states in multiple sclerosis. Mult Scler J. 2003;9(3):311-9. https://doi.org/10.1191/13524585 03ms903oa.

174. Hernandez L, Guo S, Toro-Diaz H, Carroll S, Syed Farooq SF. Peginterferon beta-1a versus other selfinjectable disease-modifying therapies in the treatment of relapsing-remitting multiple sclerosis in Scotland: a cost-effectiveness analysis. J Med Econ. 2017;20(3):228-38. https://doi.org/10.1080/136969 98.2016.1247712.

175. Pokorski RJ. Long-term survival experience of patients with multiple sclerosis. J Insur Med. 1997;29(2):101-6.

176. Hirst C, Swingler R, Compston DA, Ben-Shlomo Y, Robertson NP. Survival and cause of death in multiple sclerosis: a prospective population-based study. J Neurol Neurosurg Psychiatry. 2008;79(9):1016-21. https://doi.org/10.1136/jnnp.2007.127332.

177. Cutter GR, Zimmerman J, Salter AR, et al. Causes of death among persons with multiple sclerosis. Mult Scler Relat Disord. 2015;4(5):484-90. https://doi. org/10.1016/j.msard.2015.07.008.

178. Sadovnick AD, Ebers GC, Wilson RW, Paty DW. Life expectancy in patients attending multiple sclerosis clinics. Neurology. 1992;42(5):991-4. https://doi. org/10.1212/wnl.42.5.991.

179. The IFNB Multiple Sclerosis Study Group. Interferon beta- $1 \mathrm{~b}$ is effective in relapsing-remitting multiple sclerosis I. Clinical results of a multicenter, randomized, double-blind, placebo-controlled trial. The IFNB Multiple Sclerosis Study Group. Neurology. 1993;43(4):655-61. https://doi.org/10.1212/ wnl.43.4.655.

180. The IFNB Multiple Sclerosis Study Group and The University of British Columbia MS/MRI Analysis Group. Interferon beta- $1 \mathrm{~b}$ in the treatment of multiple sclerosis: final outcome of the randomized controlled trial. The IFNB Multiple Sclerosis Study Group and The University of British Columbia MS/ MRI Analysis Group. Neurology. 1995;45(7): 1277-85.

181. Sumelahti ML, Hakama M, Elovaara I, Pukkala E. Causes of death among patients with multiple sclerosis. Mult Scler. 2010;16(12):1437-42. https:// doi.org/10.1177/1352458510379244.

182. Koch-Henriksen N. The Danish multiple sclerosis registry: a 50-year follow-up. Mult Scler J. 1999;5(4):293-6. https://doi.org/10.1177/135245859900500418.

183. Leray E, Morrissey SP, Yaouanq J, Coustans M, Le Page E, Chaperon J, et al. Long-term survival of patients with multiple sclerosis in West France. Mult Scler J. 2007;13(7):865-74. https://doi.org/10. $1177 / 1352458507077410$.

184. Kingwell E, van der Kop M, Zhao Y, Shirani A, Zhu $\mathrm{F}$, Oger J, et al. Relative mortality and survival in multiple sclerosis: findings from British Columbia, Canada. J Neurol Neurosurg Psychiatry. 2012;83(1): 61-6. https://doi.org/10.1136/jnnp-2011-300616.

185. Kurtzke JF. Rating neurologic impairment in multiple sclerosis: an Expanded Disability Status Scale (EDSS). Neurology. 1983;33(11):1444-52. https:// doi.org/10.1212/wnl.33.11.1444.

186. Deloire MS, Bonnet MC, Salort E, Arimone Y, Boudineau M, Petry KG, et al. How to detect cognitive dysfunction at early stages of multiple sclerosis? Mult Scler. 2006;12(4):445-52. https://doi.org/10. 1191/1352458506ms1289oa.

187. Islas MAA, Ciampi E. Assessment and impact of cognitive impairment in multiple sclerosis: an overview. Biomedicines. 2019;7(1):22. https://doi. org/10.3390/biomedicines7010022.

188. Strober L, DeLuca J, Benedict RH, et al. Symbol Digit Modalities Test: a valid clinical trial endpoint for measuring cognition in multiple sclerosis. Mult Scler. 2019;25(13):1781-90. https://doi.org/10. $1177 / 1352458518808204$.

189. Strauss E, Sherman EMS, Spreen O. A compendium of neuropsychological tests: administration, norms and commentary. New York: Oxford University Press; 2006. 
190. Hernandez L, O’Donnell M, Postma M. Modeling approaches in cost-effectiveness analysis of diseasemodifying therapies for relapsing-remitting multiple sclerosis: an updated systematic review and recommendations for future economic evaluations. Pharmacoeconomics. 2018;36(10):1223-52. https:// doi.org/10.1007/s40273-018-0683-9.

191. Palace J, Duddy M, Lawton M, et al. Assessing the long-term effectiveness of interferon-beta and glatiramer acetate in multiple sclerosis: final 10-year results from the UK multiple sclerosis risk-sharing scheme. J Neurol Neurosurg Psychiatry. 2019;90(3): 251. https://doi.org/10.1136/jnnp-2018-318360.

192. Weideman AM, Tapia-Maltos MA, Johnson K, Greenwood M, Bielekova B. Meta-analysis of the age-dependent efficacy of multiple sclerosis treatments. Front Neurol. 2017;8:577.

193. Alexander J, Beygi H, Feldman P, Ashtamker N. Long-term efficacy, safety, and tolerability of threetimes weekly dosing regimen of glatiramer acetate in relapsing-remitting multiple sclerosis patients: 5-year results of the Glatiramer Acetate Low-Frequency Administration (GALA) open-label extension study (P6.378). Neurology. 2018;90(15 Suppl): 6-378.

194. Cohen JA, Tenenbaum N, Bhatt A, Zhang Y, Kappos L. Extended treatment with fingolimod for relapsing multiple sclerosis: the 14-year LONGTERMS study results. Ther Adv Neurol Disord. 2019. https://doi.org/10.1177/1756286419878324.

195. Hauser SL, Kappos L, Arnold DL, et al. Five years of ocrelizumab in relapsing multiple sclerosis. Neurology. 2020;95(13): e1854. https://doi.org/10. 1212/WNL.0000000000010376.

196. National Institute for Health and Care Excellence (NICE). Guide to the methods of technology appraisal. NICE; 2013. https://www.nice.org.uk/ process/pmg9/resources/guide-to-the-methods-oftechnology-appraisal-2013-pdf-2007975843781. Accessed 19 Nov 2020.

197. Drummond M, Barbieri M, Cook J, et al. Transferability of economic evaluations across jurisdictions: ISPOR good research practices task force report. Value Health. 2009;12(4):409-18. https://doi.org/ 10.1111/j.1524-4733.2008.00489.x.

198. Oreja-Guevara C, Ayuso Blanco T, Brieva Ruiz L, Hernández Pérez MÁ, Meca-Lallana V, Ramió-Torrentà L. Cognitive dysfunctions and assessments in multiple sclerosis. Front Neurol. 2019;10:581. https://doi.org/10.3389/fneur.2019.00581.

199. Harding K, Anderson V, Williams O, et al. A contemporary study of mortality in the multiple sclerosis population of south east Wales. Mult Scler Relat Disord. 2018;25:186-91. https://doi.org/10. 1016/j.msard.2018.08.001. 